\title{
REVIEW
}

Open Access

\section{Freezing of gait in Parkinson's disease: pathophysiology, risk factors and treatments}

\author{
Chao Gao ${ }^{1}$, Jun Liu', Yuyan Tan ${ }^{1 *}$ and Shengdi Chen ${ }^{1,2^{*}}$
}

\begin{abstract}
Background: Freezing of gait (FOG) is a common, disabling symptom of Parkinson's disease (PD), but the mechanisms and treatments of FOG remain great challenges for clinicians and researchers. The main focus of this review is to summarize the possible mechanisms underlying FOG, the risk factors for screening and predicting the onset of FOG, and the clinical trials involving various therapeutic strategies. In addition, the limitations and recommendations for future research design are also discussed.
\end{abstract}

Main body: In the mechanism section, we briefly introduced the physiological process of gait control and hypotheses about the mechanism of FOG. In the risk factor section, gait disorders, PIGD phenotype, lower striatal DAT uptake were found to be independent risk factors of FOG with consistent evidence. In the treatment section, we summarized the clinical trials of pharmacological and non-pharmacological treatments. Despite the limited effectiveness of current medications for FOG, especially levodopa resistant FOG, there were some drugs that showed promise such as istradefylline and rasagiline. Non-pharmacological treatments encompass invasive brain and spinal cord stimulation, noninvasive repetitive transcranial magnetic stimulation (rTMS) or transcranial direct current stimulation (tDCS) and vagus nerve stimulation (VNS), and physiotherapeutic approaches including cues and other training strategies. Several novel therapeutic strategies seem to be effective, such as rTMS over supplementary motor area (SMA), dual-site DBS, spinal cord stimulation (SCS) and VNS. Of physiotherapy, wearable cueing devices seem to be generally effective and promising.

Conclusion: FOG model hypotheses are helpful for better understanding and characterizing FOG and they provide clues for further research exploration. Several risk factors of FOG have been identified, but need combinatorial optimization for predicting FOG more precisely. Although firm conclusions cannot be drawn on therapeutic efficacy, the literature suggested that some therapeutic strategies showed promise.

Keywords: Freezing of gait, Parkinson's disease, Pathophysiology, Risk factor, Pharmacological treatment, Nonpharmacological treatment

\footnotetext{
* Correspondence: yuyantan00@126.com; chensd@rih.com.cn

'Department of Neurology, Ruijin Hospital Affiliated to Shanghai Jiao Tong University School of Medicine, Shanghai, China

Full list of author information is available at the end of the article
} 


\section{Background}

Freezing of gait (FOG) was defined as "brief, episodic absence or marked reduction of forward progression of the feet despite the intention to walk" $[1,2]$. Patients suddenly feel as if their feet are glued to the ground when they try to move forward. Typically, FOG lasts a couple of seconds, but this transient episode can occasionally exceed $30 \mathrm{~s}$ [3]. In rare circumstances, the patient is unable to generate any effective steps for several minutes or even longer, until compensation strategies such as cueing is provided. FOG leads to significant falls in patients with Parkinson's disease (PD) [4], which reduces patients' independence and mobility profoundly, and significantly impairs their quality of life [5].

Our understanding towards mechanism in FOG remains incomplete, and treatment of FOG is perceived by clinicians as a very challenging task. Several hypotheses have been proposed to explain the freezing phenomenon and many approaches have been applied to treat FOG. In this review, firstly, we summarized the physiology of gait control, and briefly introduced the mechanism hypotheses of FOG. Secondly, we summarized the risk factors of FOG to facilitate FOG screening in consideration of early therapeutic interventions to delay or even prevent the onset of FOG. Thirdly, various treatment approaches exist, including pharmacological and non-pharmacological treatments. Non-pharmacological treatments including invasive brain and spinal cord stimulation, noninvasive brain and vagus nerve stimulation, and physiotherapeutic approaches. Clinical trials involving various therapeutic strategies were summarized in this review. In addition, the limitations and recommendations for future research design were also discussed.

\section{Main text}

\section{Possible mechanisms underlying FOG}

The main supraspinal regions exerting critical roles in locomotion are pontomedullary reticular formation (PMRF), mesencephalic locomotor region (MLR), basal ganglia, cerebellum, and cerebral cortex [6]. MLR receives inputs from basal ganglia and cortex neurons, projects to PMRF to initiate and modulate the spinal neural circuitry to control posture and gait [7]. The major nucleis of the MLR are pedunculopontine nucleus (PPN), cuneiform nucleus and subcuneiform nucleus, in which PPN is particularly important for gait [8]. The basal ganglia receives inputs from cerebral cortex and controls voluntary motor movements through GABAergic projections to other brain regions. The primary motor cortex mainly projects to the spinal cord, and lesions in the primary motor cortex could cause contralateral paralysis. The supplementary motor area (SMA) and premotor area (PM) are also indispensable for locomotion control. The SMA and PM have dense projections to both the spinal cord and the brainstem reticular formation, which are associated with movement initiation [9]. In addition, sensation information processing and integration in the cortex are important as well. Only when the temporoparietal cortex integrates visual, proprioceptive, and vestibular sensations timely and correctly can the PM and SMA generate the motor program accurately, particularly when encountering an unfamiliar environment [10].

Several hypotheses have been proposed based on the FOG phenotype and mechanistic studies. Nieuwboer et al. [11] summarized the pathological mechanisms in the following four models: a) The threshold model [12]: Compared with non-freezers, patients with FOG present significant gait disorders such as reduced stride amplitude, impaired gait coordination and increased variability of step timing. This model assumes that when these motor deficits accumulate to a point of motor breakdown, then FOG occurs. b) The interference model [13]: The relationship of motor, cognitive and limbic circuits is proposed as both competing and complimentary. As dopamine neurons are mostly depleted in PD patients, concurrent processing of cognitive and/or limbic information during motor task will overload the information processing capacity within basal ganglia, thus leading to disordered neuronal crosstalk between these circuits. The interference between neural circuits would explain the phenomena that increasing cognitive load while performing a dual task will break down the locomotion. c) The cognitive model [14]: This modal emphasized the conflict-resolution deficit, which is one aspect of executive dysfunction. Under normal condition, people will prevent premature action and delay the response selection until resolving the conflict. In contrast, patients with FOG fail to process response conflict, impose faster response decision but with greater incongruence, thus FOG is triggered. d) The decoupling model [15]: This model regarded FOG as a disconnection between preplanned motor program and motor response. These models and hypotheses explained FOG from various perspectives. Albeit incomplete and can only partially interpret the pathophysiology and clinical phenotype of FOG, it is worth noting that these models are helpful for better understanding and characterizing FOG, and provide clues for further research exploration. More importantly, based on these models, behavior strategies can be invented and implemented for FOG treatment.

\section{Risk factors for developing FOG}

This review included the prospective studies that followed early-stage PD patients over time and the retrospective studies that clearly recorded the clinical manifestation prior to FOG onset. Many studies identified FOG related motor and non-motor symptoms by utilizing crosssection data to compare the clinical symptoms between freezers and non-freezers. Those studies were excluded as 
Table 1 A detail summary of risk factors for FOG development in Parkinson's disease

\begin{tabular}{|c|c|c|c|c|c|}
\hline Main findings & Participants & Assessment & $\begin{array}{l}\text { Follow- } \\
\text { up } \\
\text { duration }\end{array}$ & FOG define & Ref \\
\hline $\begin{array}{l}\text { CSF A } 442 \text { was a predictor of FOG in patients } \\
\text { with early PD. PIGD score, caudate DAT } \\
\text { uptake, and CSF A } 442 \text { together could predict } \\
\text { FOG within } 4 \text { years after diagnosis of PD } \\
\text { (AUC }=0.755 \text { ). }\end{array}$ & $\begin{array}{l}\text { PPMI database ( } 393 \\
\text { early do novo PD } \\
\text { without FOG at } \\
\text { baseline) }\end{array}$ & $\begin{array}{l}\text { CSF (Aß42, a-synuclein, t-tau, p-tau, A } 442 / \mathrm{t}- \\
\text { tau); motor; non-motor (olfactory, sleep, cog- } \\
\text { nition, depression, anxiety, autonomic func- } \\
\text { tion); DAT imaging (striatal region) }\end{array}$ & $\begin{array}{l}\text { Median } \\
4.0 \text { years }\end{array}$ & $\begin{array}{l}\text { MDS-UPDRS } \\
\text { item } 2.13 \text { or } \\
\text { item } 3.11 \geq 1\end{array}$ & {$[16]$} \\
\hline $\begin{array}{l}\text { DAT uptakes in the caudate nucleus and } \\
\text { putamen predicted the development of FOG. } \\
\text { Male sex, higher PIGD score, and lower MoCA } \\
\text { score were also significant predictors of FOG. }\end{array}$ & $\begin{array}{l}\text { PPMI data ( } 390 \text { early } \\
\text { do novo PD without } \\
\text { FOG at baseline) }\end{array}$ & $\begin{array}{l}\text { DAT imaging (striatal region); motor; } \\
\text { cognition }\end{array}$ & $\begin{array}{l}\text { Median } \\
4.0 \text { years }\end{array}$ & $\begin{array}{l}\text { MDS-UPDRS } \\
\text { item } 2.13 \text { or } \\
\text { item } 3.11 \geq 1\end{array}$ & [17] \\
\hline $\begin{array}{l}\text { FOGQ total score and the anxiety score were } \\
\text { the strongest predictors, and using only } \\
\text { these two factors could significantly predict } \\
\text { FOG in the next } 15 \text { months with } 82 \% \\
\text { accuracy. }\end{array}$ & $\begin{array}{l}221 \text { PD in which } 88 \\
\text { patients had FOG at } \\
\text { baseline }\end{array}$ & $\begin{array}{l}\text { Motor; non-motor (cognition, anxiety, depres- } \\
\text { sion, sleep); medication use }\end{array}$ & $\begin{array}{l}\text { Mean } \\
14 \\
\text { months }\end{array}$ & $\begin{array}{l}\text { FOGQ item } \\
3 \geq 1\end{array}$ & [18] \\
\hline $\begin{array}{l}\text { Depressive, gait speed and UPDRS-III (off vs. } \\
\text { on) were the independent predictors of fu- } \\
\text { ture FOG. }\end{array}$ & $\begin{array}{l}57 \text { PD patients } \\
\text { without FOG at } \\
\text { baseline }\end{array}$ & $\begin{array}{l}\text { Motor; non-motor (sleep, cognition, auto- } \\
\text { nomic, depression, and others); medication } \\
\text { use }\end{array}$ & $\begin{array}{l}\text { Mean } 5 \\
\text { years }\end{array}$ & $\begin{array}{l}\text { NFOGQ } \\
\text { (item } 1=1 \text { ) } \\
\text { and objective } \\
\text { observation }\end{array}$ & [19] \\
\hline $\begin{array}{l}\text { Increased risk: Onset of PD with a gait } \\
\text { disorder; higher scores of rigidity, postural } \\
\text { instability, bradykinesia and speech; and } \\
\text { longer disease duration; absence of tremor. } \\
\text { Decreased risk: Deprenyl treatment }\end{array}$ & $\begin{array}{l}\text { DATATOP data ( } 800 \\
\text { early PD in which } 57 \\
\text { patients had FOG at } \\
\text { study entry) }\end{array}$ & $\begin{array}{l}\text { Motor; non-motor (speech, cognition, depres- } \\
\text { sion); initial symptoms }\end{array}$ & $\begin{array}{l}\text { Mean } \\
14 \pm 5 \\
\text { months }\end{array}$ & $\begin{array}{l}\text { UPDRS I- } \\
\text { item14 } \geq 1\end{array}$ & [20] \\
\hline $\begin{array}{l}\text { Motor fluctuations, higher levodopa dose } \\
\text { were independent risk factors; none of the } \\
\text { cardinal features independently predicted } \\
\text { FOG. }\end{array}$ & $\begin{array}{l}232 \text { PD without FOG } \\
\text { at baseline }\end{array}$ & $\begin{array}{l}\text { Motor and motor complication; non-motor } \\
\text { (psychosis (UPDRS I item2, hallucinations or } \\
\text { delusions), cognition); medication use }\end{array}$ & 12 years & $\begin{array}{l}\text { UPDRS I- } \\
\text { item } 14 \geq 1\end{array}$ & [21] \\
\hline $\begin{array}{l}\text { Lower education, akinetic-rigid style, not } \\
\text { using dopamine receptor agonists, sleep dis- } \\
\text { orders (insomnia); cognitive disturbances } \\
\text { were predictors of FOG. }\end{array}$ & $\begin{array}{l}248 \text { early PD without } \\
\text { FOG at baseline }\end{array}$ & $\begin{array}{l}\text { Motor; non-motor (anxiety; depression); } \\
\text { medication use; }\end{array}$ & 3 years & $\begin{array}{l}\text { FOGQ item } \\
3 \geq 1 \text { and } \\
\text { objective } \\
\text { observation }\end{array}$ & [22] \\
\hline $\begin{array}{l}\text { Longer disease duration, visuospatial function } \\
\text { deterioration, onset in lower limbs, presence } \\
\text { of festination, falls, and hallucinations were } \\
\text { independent predictors of FOG. }\end{array}$ & $\begin{array}{l}225 \text { PD without FOG } \\
\text { at baseline }\end{array}$ & $\begin{array}{l}\text { Motor (including festination and fall); non- } \\
\text { motor (anxiety, depression, cognition); medi- } \\
\text { cation use; }\end{array}$ & 3 years & $\begin{array}{l}\text { FOGQ item } \\
3 \geq 1 \text { and } \\
\text { objective } \\
\text { observation }\end{array}$ & [23] \\
\hline $\begin{array}{l}\text { Baseline processing speed, learning and } \\
\text { daytime sleepiness were predictive of FOG. }\end{array}$ & $\begin{array}{l}\text { PPMI database ( } 50 \\
\text { PD }+ \text { FOG, and } 50 \text { PD- } \\
\text { FOG at the fourth } \\
\text { year) }\end{array}$ & $\begin{array}{l}\text { Motor; non-motor (cognition, anxiety, depres- } \\
\text { sion, sleep) }\end{array}$ & 4 years & $\begin{array}{l}\text { MDS-UPDRS } \\
\text { item } 2.13 \geq 1\end{array}$ & [24] \\
\hline $\begin{array}{l}\text { A more severe depletion of presynaptic } \\
\text { dopamine (low } 1231 \text {-FP-CIT binding in the pu- } \\
\text { tamen and striatum) in early PD predicted } \\
\text { FOG }\end{array}$ & $\begin{array}{l}41 \text { early PD without } \\
\text { FOG at baseline }\end{array}$ & $\begin{array}{l}\text { Motor (including falls) and motor } \\
\text { complication; DAT imaging (striatal region); } \\
\text { medication use }\end{array}$ & $\begin{array}{l}9.51 \pm \\
3.18 \\
\text { years }\end{array}$ & $\begin{array}{l}\text { UPDRS II- } \\
\text { item14 } \geq 1\end{array}$ & [25] \\
\hline $\begin{array}{l}\text { PD group with moderate to severe WMH } \\
\text { showed a higher risk of developing FOG (HR, } \\
3.29 ; 95 \% \mathrm{Cl}, 1.79-6.05 ; P<0.001) \text { than the PD } \\
\text { patients with minimal WMH. }\end{array}$ & $\begin{array}{l}268 \text { patients with de } \\
\text { novo } P D \text { without FOG }\end{array}$ & $\begin{array}{l}\text { MRI WMH; motor (UPDRS-III, phenotype); } \\
\text { non-motor (olfactory, cognition, depression) } \\
\text { DAT imaging; medication; vascular risk factors }\end{array}$ & $\begin{array}{l}>3 \\
\text { years }\end{array}$ & $\begin{array}{l}\text { Inquiry and } \\
\text { observation }\end{array}$ & [26] \\
\hline
\end{tabular}

A total of 11 longitudinal follow-up studies were reviewed and summarized. Main findings, recruited participants and their FOG define criteria, assessment parameters, follow-up duration were all included

CSF Cerebrospinal fluid, FOG Freezing of gait, PD Parkinson's disease, PIGD Postural instability and gait difficulty, DAT Dopamine transporter, AUC Area under the ROC curve, PPMI Parkinson's Progression Markers Initiative, MDS-UPDRS Movement Disorder Society-Sponsored Revision of the Unified Parkinson's Disease Rating Scale, MoCA Montreal Cognitive Assessment, FOGQ Freezing of Gait-Questionnaire, NFOGQ New Freezing of Gait Questionnaire, DATATOP Deprenyl and tocopherol antioxidative therapy of parkinsonism, WMH White matter hyperintensitie

they cannot differentiate the symptoms prior to FOG from the accompanying symptoms of FOG. A total of 11 longitudinal follow-up studies were reviewed and summarized (Table 1). For these studies, cox proportional-hazards regression analyses $[16,17,20,26]$ or logistic regression analysis $[18,19,22-25]$ were performed to identify the factors predictive of FOG except one study that used generalized estimating equations [21]. Here, we elaborated the risk factors including demographic information, motor symptoms, non-motor symptoms, neuroimaging, fluid 
parameters, and medication use. Current limitations and recommendations for future researches will also be discussed. A list of the evidence supporting and refuting the following variables as risk factors of FOG was provided in Table 2.

\section{Demographic risk factors \\ Male sex}

Two studies using the Parkinson's Progression Markers Initiative (PPMI) data included 390 (393) patients with newly diagnosed PD at baseline $[16,17]$. During a median follow-up of 4.0 years, male sex was found to be an independent risk factor of FOG (Hazard ratio $(H R)=1.512$, $P=0.046)$ [16]. This finding is consistent with another study that included 41 patients with a mean follow-up disease duration of $9.51 \pm 3.18$ years [25]. Of these $41 \mathrm{PD}$ patients, 15 patients developed FOG at the end of follow-up, in which 14 patients were males. Besides these follow-up studies, a previous cross-section study that analyzed 6620 PD patients also found that males were more likely to have FOG than females (Odds ratio $(\mathrm{OR})=1.19, P=$ 0.011) [27]. A number of studies have reported the existence of gender difference on specific motor or non-motor symptoms in PD. Estrogen may play a protective role in PD by influencing dopamine synthesis and release or modulating dopamine receptor expression and function [28]. However, this finding was not observed in some other studies [18-24, 26].

\section{Low education level}

Zhang et al's study followed 248 early PD patients without FOG at baseline for 3 years and found that patients with a lower education level ( $\leq 9$ years of education) were more prone to have FOG $(\mathrm{OR}=0.012, P<0.001)$ [22] This study provided an explanation that patient with a higher education had a better understanding of PD and

Table 2 A list of the evidence supporting and refuting the following variable as a risk factor of freezing of gait

\begin{tabular}{|c|c|c|}
\hline & Supporting evidence ${ }^{a}$ & Refuting evidence $^{a}$ \\
\hline \multicolumn{3}{|l|}{ Demographic risk factors } \\
\hline Male sex & {$[16,17,25]$} & {$[18-24,26]$} \\
\hline Low education level & {$[22]$} & {$[19,23,24]$} \\
\hline Onset age & & {$[16,17,20-23,25,26]$} \\
\hline Age & & {$[18,19,21-25]$} \\
\hline Baseline longer disease duration & {$[20,23]$} & {$[16-19,21]^{b}$} \\
\hline \multicolumn{3}{|l|}{ Motor symptoms } \\
\hline Gait disorders & {$[16-21,23]$} & [22] \\
\hline Motor phenotype & {$[16,17,21,22]$} & {$[18,19,25]$} \\
\hline Motor fluctuation & {$[21]$} & [23] \\
\hline Balance, festination and falls & Festination and falls [23], balance [20] & Balance [19] \\
\hline \multicolumn{3}{|l|}{ Non-motor symptoms } \\
\hline Cognitive disturbance & {$[16,17,22-24]$} & [18-21] \\
\hline Depression & {$[19,20,22]$} & {$[16,23,24]$} \\
\hline Anxiety & {$[18]$} & {$[16,23,24]$} \\
\hline Sleep & Insomnia [22], daytime sleepiness [24] & $\operatorname{RBD}[16,18,24]$, daytime sleepiness $[16,23]$ \\
\hline Others & Speech problems [20], hallucination [23] & \\
\hline \multicolumn{3}{|l|}{ Neuroimaging and fluid parameters } \\
\hline Lower striatal DAT update & {$[16,17,25]$} & \\
\hline White matter hyperintensities & {$[26]$} & \\
\hline CSF A $A 42$ & {$[16]$} & \\
\hline \multicolumn{3}{|l|}{ Medication use } \\
\hline High LEDD & {$[21]$} & {$[18,19,23,26]$} \\
\hline Dopamine agonist & & {$[22]$} \\
\hline
\end{tabular}

Demographic information, motor symptoms, non-motor symptoms, neuroimaging, fluid parameters, and medication use were all included DAT Dopamine transporter, CSF Cerebrospinal fluid, LEDD Levodopa equivalent daily doses

${ }^{a}$ Only the prospective studies that followed early-stage PD patients over time and the retrospective studies that clearly recorded the clinical manifestation prior to FOG onset were cited here

${ }^{b}$ Baseline disease duration instead of the whole disease duration was analyzed in those cited studies. Relatively short disease duration might be the reason for failure to identify disease duration as a risk factor 
better compliance, leading to better treatments. However, this finding was not found in other three follow-up studies [19, 23, 24]. Although cognitive impairment is involved in the pathogenesis of FOG, whether level of education can be used as an indicator of cognitive reserve is still under debate [29].

\section{Onset age and age}

Eight studies recorded the age of onset and showed that there was no relationship between the age of onset and FOG development [16, 17, 20-23, 25, 26]. Seven studies recorded age at baseline $[18,19,21-25]$, in which only one study showed that older age was a risk factor of FOG, but the statistical significance was weak $(P=0.054)$ [18]. Two previous cross-sectional surveys including 6620 and 683 PD patients respectively also found that age was not the predictor of FOG in PD [27, 30].

\section{Longer disease duration}

It is well recognized that the duration of the disease is a crucial risk factor of FOG. FOG tends to occur in the later stages of PD. Early onset FOG should be suspected of other parkinsonism, such as progressive supranuclear palsy [31]. In a retrospective study of 800 patients with early PD, only $7.1 \%$ of patients experienced FOG [20]. However, with prolonged disease progression and disease duration, FOG can affect $53 \%$ of patients in the advanced stages of the disease [32]. A previous prospective study [20] and several cross-sectional studies [27, 33, 34] also found that patients with longer disease duration were more likely to develop FOG episodes. However, other studies failed to identify disease duration as a risk factor of FOG [16-19, 21]. The reason might be that the baseline disease duration instead of the whole disease duration till the end of follow-up were analyzed between non-freezers and transitional freezers, and most patients included were early PD patients who had relatively short disease duration at baseline.

\section{Motor symptoms \\ Gait disorders}

The Freezing of Gait-Questionnaire (FOGQ) total [18](OR = $2.34, P=0.01$ ), gait speed (on state) assessed by wearable sensors (OR $=0.01, P=0.032)$ [19], lower limbs as the onset site $(\mathrm{OR}=2.632, P=0.013)[20,23]$ were found to be risk factors of FOG, respectively. In addition, several studies found that Movement Disorder Society-Sponsored Revision of the Unified Parkinson's Disease Rating Scale (MDS-UPDRS) motor score especially postural instability and gait difficulty (PIGD) score could predict FOG development [16, 17, 21]. These findings indicated that the gait impairment had already existed even patients didn't present freezing episodes at the early stage of disease. This can be explained by the pathophysiology of gait control, which has been reviewed previously $[8,10,35]$. Lesions in any part of gait control system may cause abnormal gait performance. When gait impairment involved the key regions particularly important for gait, such as PPN, or when compensation was not achieved with disease progression, patients would suffer from FOG.

\section{Motor phenotype}

Postural instability and gait difficulty (PIGD) was identified as a risk factor of FOG in PD patients [16, 17, 21]. PD patients with PIGD not only showed more severe striatal dopaminergic terminal loss, but also presented with extrastriatal non-dopaminergic denervation compared to patients without FOG [36]. Additionally, PIGD symptoms were apparently associated with grey matter atrophy in motor-related regions and decreased functional connectivity [37]. Cognitive impairment was also significantly correlated with PIGD phenotype [38]. These mechanisms might all contribute to FOG development. However, another study did not show the difference in PIGD phenotype between non-freezers and transitional freezers at baseline [19]. If motor phenotype was classified as tremor dominant and akinetic rigid phenotype, results were controversial [22, 25]. In Zhang et al's study, patients with akinetic-rigid phenotype were more likely to suffer from FOG 3 years later $(\mathrm{OR}=4.881, P=0.024)$ [22]. However, Djaldetti $R$ et al's study found no difference of motor phenotype between non-freezers and transitional freezers at baseline [25]. Ehgoetz et al. classified motor phenotype as tremor-dominant (TD) or nonTD phenotype, and didn't reveal that the motor phenotype was a risk factor of FOG [18].

\section{Motor fluctuation}

Motor fluctuation was found to be a risk factor of FOG in Forsaa's study. This study included 232 PD patients without FOG at baseline and found that non-freezers who presented with motor fluctuations at study entry were at more than 3-fold increased risk to develop incident FOG during the 12-year follow-up period as compared with patients without motor fluctuations at baseline [21]. Another study included 225 PD patients and did not reveal didn't reveal motor fluctuation as a risk factor of FOG, but found that frequency of motor fluctuation at baseline was much higher in transitional freezers than non-freezers (20\% vs. $10 \%, P=0.056)$ [23]. Motor fluctuations are supposed to be more closely related to the severity of dopamine depletion in the basal ganglia [39], which can partly explain the phenomenon that motor fluctuation may precede the onset of FOG.

\section{Balance, festination and falls}

Postural control and balance $[40,41]$ were affected more significantly in PD patients with FOG compared with non-FOG group. FOG often occurs when turning also 
suggests that the postural control impairment probably contributes to freezing. However, whether balance impairment is an accompanying symptom of FOG or a risk factor of FOG remains unclear. In Giladi N et al's study, balance was assessed by two UPDRS subitems, and they found balance impairment predicted FOG development (HR $=1.94, P=0.0005)$ [20]. However, Herman T et al. using Berg balance scale and Activities-specific balance confidence scale to assess balance and fear of falling failed to confirm balance impairment as a risk factor in logistic regression model, although transitional freezers had significantly worse Berg balance scale score than non-freezers at baseline [19]. For festination and falls, only one study reported that presence of festination or falls at baseline was risk factors of FOG [23]. The potential mechanism underlying the relationship between gait festination and freezing in PD has been reviewed and discussed in previous reviews [42, 43]. Briefly, festination is hypothesized to be caused by the progressive delays in the timing of phasic motor cues from the internal globus pallidus to the SMA and PM. Thus the step becomes shorter and shorter. When the defect reaches the limit presenting with extremely slow or absence of the phasic cues, the motor cortical regions are not provided with phasic cues necessary to enable them to generate force for the next step in sequence, leading to the subsequent motor block-FOG.

\section{Non-motor symptoms}

\section{Cognitive disturbance}

Cognitive impairment as an independent risk factor of FOG has been found by several studies [16, 17, 22]. The cognitive function domains with predictive value for FOG include baseline processing speed, learning ability [24] and visuospatial/executive abilities [23]. The involvement of cognitive impairment in FOG pathophysiology has been explained by previously proposed cognitive model [11, 14]. This model emphasized conflict-resolution deficit in executive dysfunction. Under normal condition, people will prevent premature action and delay the response selection until resolving the conflict. In contrast, when patients fail to process response conflict, impose faster response decision but with greater incongruence, FOG is triggered. Additionally, the beneficial effect of cognitive training for FOG also reflected that the pathophysiological mechanism of FOG linked to cognitive dysfunction [44]. Future studies would better enroll the PD patients without FOG at baseline, and test whether cognitive training can prevent or delay FOG development. It is worth noting that although much evidence supported cognitive impairment was a risk factor of FOG, there were still several studies didn't confirm this finding [18-21].

\section{Depression and anxiety}

One study including 57 PD patients without FOG at baseline showed that depression was a strong risk factor for FOG development $(\mathrm{OR}=10.93, P=0.003)$. Eighty percent of the subjects who had marked depressive symptoms at baseline (Geriatric Depression Scale 25 ) developed FOG at mean 5 years' follow-up. In contrast, only $27 \%$ of those with few depressive symptoms at baseline became freezers $(p<0.001)$ [19]. A longitudinal study recruited 221 PD patients with over 1 year followup found that the anxiety score and FOGQ total score were the strongest predictors, and these two factors could significantly predict FOG in the next 15 months with $82 \%$ accuracy [18]. Ehgoetz et al. used the virtual reality-based functional magnetic resonance imaging approach also confirmed the association of limbic network with FOG. They found that during freezing, the coupling between limbic network (cortical and subcortical) and ventral striatum, and the coupling between limbic and cognitive control network were increased compared to normal foot tapping. In contrast, anti-coupling between the cortical and subcortical limbic network and within the subcortical network was found during freezing [45]. However, other studies did not reveal depression or anxiety as a risk factor of FOG, but found the depression or anxiety score was significantly higher at baseline in transitional freezers than non-freezers $[16,23]$.

\section{Sleep}

Kim et al's study using PPMI database found that REM Sleep Behavior Disorder (RBD) screening questionnaire (RBDSQ) score was higher in transitional freezers compared with non-freezers, and univariable analysis also confirmed that RBD may increase the risk for FOG development. However, multivariable analysis in the same study failed to establish its risk factor effect [16]. Although gait disorders have been found in polysomnographyconfirmed RBD patients [46, 47] and it was hypothesized that FOG and RBD might share a common physiopathology [48], the relationship between RBD and FOG was not confirmed [16, 18, 24]. In other two studies, RBDSQ at baseline didn't show significant difference between transitional freezers and non-freezers [18, 24], which was supported by a previous finding that there was no freezing difference between the patients with probable RBD and without RBD [49]. Other studies explored the relationship of insomnia or daytime sleepiness with FOG. One study demonstrated that insomnia assessed by Hamilton Depression Rating Scale $(\mathrm{OR}=2.418, P=0.036)$ was an independent risk factor for FOG development [22]. Three studies evaluated daytime sleepiness, but the results were inconsistent [16, 23, 24]. In Bank et al' s study, daytime sleepiness assessed by Epworth Sleepiness Scale (ESS) was identified as a risk factor of future FOG [24]. However, 
Kim et al' s study failed to establish its risk factor effect, although they found that ESS score was higher in transitional freezers compared with non-freezers, and ESS may increase the risk for FOG development in univariable analysis [16]. Another study didn't find the difference of daytime sleepiness between non-freezers and transitional freezers at baseline [23].

\section{Others}

Speech disturbance [50] was more frequent in patients with FOG. The DATATOP (Deprenyl and tocopherol antioxidative therapy of parkinsonism) study also found that patients with speech problems at baseline were more likely to develop FOG at the end of follow-up [20]. Another study evaluated hallucination using UPDRS part I subitem and found that hallucination was a risk factor of FOG [23]. These findings need to be confirmed by future studies and which type of speech disorder and hallucination related to FOG needs to be evaluated.

\section{Neuroimaging and fluid parameters Striatal DAT update}

Several studies have found that presynaptic striatal dopaminergic depletion examined by dopamine transporter (DAT) uptake predicted the later development of FOG in de novo PD $[16,17,25]$. Caudate DAT uptake was more significantly related to FOG development compared with putamen [16]. The combined model integrating the caudate DAT uptake, PIGD score, and cerebrospinal fluid (CSF) A 42 together can predict FOG within 4 years after diagnosis of PD (area under the curve 0.755, 95\% CI $0.700-0.810$ ). These findings demonstrated a direct association between the initial presynaptic striatal dopamine loss and the subsequent development of FOG in patients with early PD.

\section{White matter hyperintensities (WMH)}

Recently one study retrospectively reviewed medical records of 268 patients with de novo PD (follow-up $>3$ years), and evaluated the longitudinal effects of WMH on the development of FOG using cox regression model [26]. Results showed that after adjusting for age, sex, striatal DAT availability and levodopa equivalent dose, the PD group with moderate to severe WMH showed a higher risk of developing FOG $(\mathrm{HR}=3.29, P<0.001)$ than the PD patients with minimal WMH. This study was consistent with previous studies which showed that increased WMH burden was associated with severe motor deficits, especially axial motor impairments [51, 52]. Although the mechanisms linking WMH and motor disability are not fully understood, diffuse white matter damage including major cortico-cortical, motor-related cortico-fugal and several striato-frontal tracts are involved in the gait control network, which may contribute to FOG development.

\section{CSF $A \beta 42$}

One recent study [16] using the PPMI data included 393 newly diagnosed PD patients without FOG at baseline aimed to explore whether CSF biomarker changed prior to FOG occurrence. Beta-amyloid 1-42 (A $\beta 42)$, $\alpha$ synuclein, total tau, phosphorylated tau, and the calculated ratio of $\mathrm{A} \beta 42$ to total tau in CSF at baseline was evaluated. Cox proportional-hazards regression analysis was performed to identify factors predictive of FOG. They found that in multivariable Cox analysis, only A 342 of those CSF biomarkers was associated with the development of FOG $(\mathrm{HR}=0.997, P=0.009)$. This study proposed the possible mechanisms underlying $A \beta$ and FOG. Firstly, $A \beta$ plaque influences the neural circuitry associated with FOG. Secondly, A $\beta$ may promote other proteins such as $\alpha$-synuclein to misfold and accelerate disease progression; Thirdly, $A \beta$ pathology is related to cognitive dysfunction, and cognitive dysfunction is a contributor for FOG. Those explanations were made based on brain $A \beta$ plaque pathology. Although $A \beta$ in CSF inversely correlated with $A \beta$ plaque formation in brain reported by Fagan et al. [53], there is lack of direct evidence of brain $A \beta$ pathology and FOG in this study.

\section{Medication use}

Several studies recorded levodopa equivalent daily doses (LEDD) at baseline and explored whether it could be a factor to predict FOG development. In Forsaa EB's study, higher LEDD was found to be an independent risk factor of FOG in a cohort of 234 PD patients with 12 years' follow-up (OR $=1.30 / 100 \mathrm{mg}, P=0.009)$ [21]. Ou $\mathrm{R}$ et al's study showed that the frequency of levodopa usage was higher in transitional freezers compared with non-freezers at baseline ( $72 \%$ vs.54\%, $P=0.014)$ [23]. Two other studies found that transitional freezers had higher LEDD compared with non-freezers at baseline $[18,23]$, but failed to identify LEDD as a risk factor of FOG [18, 19, 23, 26]. However, clinicians practicing in the early years of levodopa introduction clearly felt they were witnessing a novel phenomenon that had not existed in the pre-levodopa era. Recently, Koehler PJ and his colleague reviewed films and medical textbooks before 1972. They chose 1972 as all patients in available films were levodopa naive by then. They found that before the introduction of levodopa, FOG was not as common as it is nowadays and thus concluded that FOG episodes have increased after the introduction and longterm use of levodopa [54]. They gave explanations as follows: before levodopa was applied in clinic, motor symptoms were not well controlled and patients were too disabled to walk and demonstrate FOG; clinicians 
knew little about how to provoke FOG and seldom observe it; patients had short life span and disease duration might be too short to develop FOG; another possibility might be that FOG occurrence was induced by levodopa. According to the response to levodopa, FOG was classified as dopamine responsive FOG, dopamine resistant FOG and dopamine induced FOG (caused by administration of dopaminergic medication) [55]. It is hypothesized that peak-dose of oral levodopa caused dopaminergic over-stimulation, leading to dysfunction of forntalsubcortical circuits, which prompt "high-order" gait abnormalities such as FOG [56]. Future studies should evaluate whether and how chronic levodopa use increase the frequency of FOG events. Besides levodopa, Deprenyl treatment was strongly associated with a decreased risk for developing FOG [20]. Additionally, whether dopamine agonists (DA) increase the risk of developing FOG remains controversial $[22,32,55,57]$. One study followed 248 early PD patients without FOG in which 128 patients developed FOG 3 years later. They found that the proportion of DA use was significantly higher in non-freezers than transitional freezers at baseline $(60.8 \%$ vs. $10.9 \%, P<$ 0.001). Binary logistic regression further established that not use DA was a risk factor of future FOG development [22]. However, several studies claimed that DA may increase the risk for developing FOG. A retrospective study showed that longer treatment with DA contributed to the appearance of FOG [32]. Bloem et al. also stated that based on their experience they had seen clear FOG induced by DA monotherapy [55]. In addition, ropinirole medication might deteriorate FOG in dopamineresponsive FOG patients with PD in a clinical trial [57].

\section{Limitation and recommendations for risk factor related researches for FOG}

Firstly, FOG was assessed by subjective questionnaires in most studies. Showing the video to patients in testing new freezing of gait questionnaire (NFOGQ) [58] will help patients to understand FOG [55]. Using objective sensors to detect FOG will be more accurate to recognize FOG. Secondly, the follow-up was not long enough for some patients to develop FOG by the end of study, thus whether these risk factors could predict FOG over longer periods remains unclear. Thirdly, these studies didn't differentiate "on" and "off" FOG. FOG is regarded to have different mechanisms under "on" and "off" medication states. Further studies are needed to explore the risk factors of specific type of FOG. Fourthly, these studies only explored the relationship between baseline parameters and FOG development except $\mathrm{Ou}$ R's study [23], which calculated the changes of annual UPDRS. Thus future studies would better take disease progression rate into account by measuring the annual changes of scales, imaging or CSF markers. Meanwhile, some clinical domains should be assessed more comprehensively and objectively, such as using wearable sensors to evaluate gait disorders and balance impairments and neuropsychological battery to assess specific domain of cognitive dysfunction. Additionally, neuroimaging studies combining both structure and functional connectivity would better be explored prior to FOG onset and examined whether it can be used as an independent risk factor. At last, prospective studies including a larger sample of patients with longer follow-up period is strongly recommended.

\section{Drug treatment (The details of clinical trials are listed in Table 3)}

Levodopa and levodopa-carbidopa intestinal gel (LCIG)

Robust evidence supports that dopamine replacement therapy with levodopa is the first choice for FOG treatment in PD [55]. Levodopa can significantly decrease the frequency and number of FOG episodes [3, 59]. FOG is more common and more prolonged during the off-state than during the on-state $[3,30,96]$, and levodopa can reduce both off time and FOG severity [3]. To be note, the "threshold" to improve FOG is higher than the threshold to improve other motor signs in some patients, thus increased levodopa dosage without deterioration of other motor symptoms may potentially be effective [97]. However, there still exist numerous patients whose FOG is resistant to levodopa [30]. Continuous intra-jejunal infusion of LCIG is an effective advanced therapy for the treatment of motor fluctuations in PD [98, 99]. LCIG is administered via percutaneous endoscopic gastrostomy with a jejunal extension tube. The suspension form of carbidopa and levodopa can be delivered continuously into the intestine and plasma levodopa concentration can maintain stable. One retrospective study including 65 advanced PD showed that with LCIG treatment, FOG presented in 22\% of patients at 1-year follow-up compared to $46 \%$ at the baseline [60]. Another retrospective study including $91 \mathrm{ad}-$ vanced PD with $18 \pm 8.4$ months' follow-up also showed that gait disorders (freezing, festination, postural instability) improved in $61.4 \%$ of patients [61]. These results were supported by other clinical trials $[62,63]$. Besides, longterm effectiveness of LCIG on FOG has also been demonstrated by two prospective studies. Sensi M et al. evaluated the long-term outcome in 28 PD patients, in which 17 patients reached the 24-month follow-up. Results showed that FOGQ at 6 months $(P=0.001)$ and 2 years $(P=0.03)$ were significantly lower than the pre-treatment condition [64]. Vijiaratnam $\mathrm{N}$ et al. also found that FOGQ improved $24 \%(11.9 \pm 5.5$ vs. $9.1 \pm 5.3, P=0.007)$ at 6 months in 25 PD patients [65]. Possible mechanism is that increasing "On" time by LCIG may lead to benefits on FOG when freezing episodes happen during the "Off" time. Importantly, two pilot studies found that LCIG can also improve 
Table 3 Clinical trials of drug treatments for freezing of gait in Parkinson's disease

\begin{tabular}{|c|c|c|c|c|c|}
\hline $\begin{array}{l}\text { Study } \\
\text { reference }\end{array}$ & Participants & Study design & Treatment & Main findings & FOG subtype \\
\hline \multicolumn{6}{|c|}{ Levodopa } \\
\hline [3] & $\begin{array}{l}19 \text { PD with } \\
\text { FOG }\end{array}$ & $\begin{array}{l}\text { Prospective, open-label, } \\
\text { uncontrolled }\end{array}$ & $\begin{array}{l}\text { Patients were examined during } \\
\text { "Off" and "On" states that } \\
\text { approximately } 1 \mathrm{~h} \text { after they took } \\
\text { their regular morning dose of } \\
\text { levodopa. }\end{array}$ & $\begin{array}{l}\text { Levodopa significantly decreased } \\
\text { frequency and the number of } \\
\text { FOG episodes (Video recorded). }\end{array}$ & $\begin{array}{l}\text { Unknown, but } \\
\text { levodopa } \\
\text { induced FOG } \\
\text { was excluded }\end{array}$ \\
\hline [59] & $\begin{array}{l}20 \text { PD with } \\
\text { FOG }\end{array}$ & $\begin{array}{l}\text { Prospective, open-label, } \\
\text { uncontrolled }\end{array}$ & $\begin{array}{l}\text { Similar with the above study but } \\
\text { took } 1.5 \text { times the usual levodopa } \\
\text { dose }\end{array}$ & $\begin{array}{l}\text { FOG improved (customized FOG } \\
\text { score and FOGQ). }\end{array}$ & Unknown \\
\hline
\end{tabular}

\section{Levodopa-carbidopa intestinal gel (LCIG)}

[60] 65 advanced Observational, retrospective, a PD review of medical records

[61] 91 advanced PD

Observational, retrospective, a review of medical records

[62] 32 advanced PD with FOG

Observational, retrospective, a review of medical records

[63] 177 advanced Observational, retrospective, PD, in which multi-center, cross-sectional, 122 patients uncontrolled with FOG

[64] $28 \mathrm{PD}$

[65] $25 \mathrm{PD}$

[66] 5 PD with FOG Prospective, open label, uncontrolled

[56] 7 PD with FOG Prospective, open label controlled, unrandomized

\section{Dopamine agonist}

$\begin{array}{lll}\text { [67] } 36 \text { PD } & \begin{array}{l}\text { Prospective, open label, } \\ \text { uncontrolled }\end{array} \\ \text { [68] } & \begin{array}{l}111 \text { PD, in } \\ \text { which } 54 \\ \text { patients with } \\ \text { FOG }\end{array} & \begin{array}{l}\text { Prospective, open label } \\ \text { controlled, unrandomized }\end{array} \\ \text { [69] } 10 \text { PD with } & \begin{array}{l}\text { Prospective, open label, } \\ \text { FOG }\end{array} & \text { uncontrolled }\end{array}$

\section{Monoamine oxidase B inhibitors}

\section{Selegiline}

$\begin{array}{ll}\text { 14 PD with } & \text { Prospective, open label, } \\ \text { [70] FOG } & \text { uncontrolled }\end{array}$

Mean duration of LCIG therapy was 3.7 years

Mean time of follow up of $18 \pm$ 8.4 months

Mean duration of LCIG therapy

Mean duration of LCIG therapy was 34.7 months, $80.8 \%$ of patients $\geq 12$ months

$17 / 28$ patients reached the $24-$ month follow-up

20 patients continued on treatment to 6 months.

\section{$24 \mathrm{~h} \mathrm{LCIG} \mathrm{therapy,} 6$ months}

Evaluations were performed in "On" state $(60-90$ min after taking the morning oral levodopa or $\mathrm{LCIG)}$

Pramipexole treatment for 3 months (started at $0.125 \mathrm{mg} /$ day and increased to $1.5 \mathrm{mg} /$ day) .

Rotigotine transdermal patch (9$27 \mathrm{mg} /$ day), pramipexole LA (1.5$4.5 \mathrm{mg} /$ day), ropinirole CR (8-16 $\mathrm{mg} /$ day) for at least 6 months

Acute test of subcutaneous apomorphine bolus in the morning at "off" state, without other medication was $2.59 \pm 1.12$ years

FOG improved (FOG present only Unknown in $22 \%$ of patients at 1 year follow-up compared to $46 \%$ at baseline).

Gait disorders (freezing, festination, postural instability) improved in $61.4 \%$ of patients (three point scale).

FOG that present in OFF condition and improved but did not disappear completely in ON condition can be further improved by LCIG (UPDRS freezing score).

FOG improved in $76.2 \%$ of patients (subjective assessment by clinicians).

FOG improved (FOGQ)

FOG improved (FOGQ)

$360^{\circ}$ turn time reduced, FOG improved (FOGQ) and fall frequency reduced

FOG improved on LCIG (FOGQ and UPDRS freezing score)

FOG improvement (FOGQ)

FOG improvement in Rotigotine group (FOGQ)

No improvement (subjective assessment)

Addition or increase in dose of selegiline, average dose: $4.0 \mathrm{mg} /$ day for 3 months
FOG improved in $7 / 14$ patients (FOGQ)
Unknown

Unknown

Unknown

31 patients with responsive FOG and one with resistantFOG

Unknown

Resistant

Resistant

48 patients with "Off" FOG and 6 with "Off and On" FOG

FOG occur in both "Off" and "On" state

\section{Rasagiline}


Table 3 Clinical trials of drug treatments for freezing of gait in Parkinson's disease (Continued)

\begin{tabular}{|c|c|c|c|c|c|}
\hline $\begin{array}{l}\text { Study } \\
\text { reference }\end{array}$ & Participants & Study design & Treatment & Main findings & FOG subtype \\
\hline [71] & $\begin{array}{l}687 \text { PD in } \\
\text { which } 278 \\
\text { patients with } \\
\text { FOG }\end{array}$ & $\begin{array}{l}\text { Prospective, double-blind, ran- } \\
\text { domized, placebo-controlled }\end{array}$ & $\begin{array}{l}\text { Oral rasagiline ( } 1 \mathrm{mg} \text { once daily), } \\
\text { entacapone ( } 200 \mathrm{mg} \text { with every } \\
\text { levodopa dose), or placebo for } 18 \\
\text { weeks }\end{array}$ & $\begin{array}{l}\text { FOG improved by Rasagiline } \\
\text { (UPDRS-PIGD, UPDRS-freezing } \\
\text { score) }\end{array}$ & Unknown \\
\hline$[72]$ & $\begin{array}{l}42 \text { PD with } \\
\text { FOG }\end{array}$ & $\begin{array}{l}\text { Prospective, open label, } \\
\text { uncontrolled, multicenter }\end{array}$ & $\begin{array}{l}1 \text { mg rasagiline daily as an add-on } \\
\text { therapy for } 3 \text { months }\end{array}$ & $\begin{array}{l}\text { FOG improved after } 1,2 \text { and } 3 \\
\text { months of therapy (FOGQ) }\end{array}$ & Unknown \\
\hline [73] & $\begin{array}{l}18 \text { PD with } \\
\text { FOG }\end{array}$ & $\begin{array}{l}\text { Prospective, open label, } \\
\text { uncontrolled, }\end{array}$ & $\begin{array}{l}1 \text { mg rasagiline daily as an add-on } \\
\text { therapy for } 90 \text { days }\end{array}$ & $\begin{array}{l}\text { No overall improvement } \\
\text { (Objective FOG counts and } \\
\text { duration) }\end{array}$ & Resistant \\
\hline
\end{tabular}

\section{Methylphenidate (MPH)}

\section{9 advanced}

[74] PD with FOG who had received STNstimulation

17 STN-

[75] stimulated patients with advanced $P D$ and gait disorders

5 PD with FOG Prospective, open label, uncontrolled

17 PD with

[77] moderate gait impairment

\section{Istradefylline}

[78] with FOGQ $12.14 \pm 5.82$

31 PD patients Prospective, open label, [79] with FOG

\section{Antidepressants}

52 PD with re randomized, controlled depressive multicenter

\section{L-DOPS, droxidopa} [81] FOG

Randomized, open label, controlled

13 advanced Prospective, open label, [82] PD with FOG uncontrolled

\section{Amantadine}

[83] $\quad 11 \mathrm{POG}$
MPH (1 mg/kg per day) or placebo capsules for 90 days

A daily dose of $1 \mathrm{mg} / \mathrm{kg}$ of MPH three times daily) for 3 months, including a 1-month titration phase

A single oral administration of 10 mg MPH. Reassessment $2 \mathrm{~h}$ later.

FOG improved (total walking

time, total freezing time, number of freezing episodes and the non-freezing walking time during an "8" trajectory).

$\mathrm{MPH}$ (maximum, up to $80 \mathrm{mg} /$ day) No improvement (FOGQ)

Unknown or placebo for 12 weeks and crossed over after a 3-week washout.

$20 \mathrm{mg}$ Istradefylline daily for 1 FOG improved (FOGQ)

Unknown month

$20 \mathrm{mg}$ Istradefylline daily for 4 weeks, followed by 20 mg/day or an $40 \mathrm{mg} /$ day for 8 weeks

FOG improved (FOGQ, NFOGQ, and MDS-UPDRS Part III (ONstate) gait-related items total score)

Paroxetine 20 mg/day or $25 \mathrm{mg} /$ day; escitalopram 10 mg/day; duloxetine

40 mg/day; 8 weeks' maintenance period and 2 weeks' incremental period

L-DOPS and entacapone initially $100 \mathrm{mg}$ per day, increase by 100 mg increments every 2 days up to $100 \mathrm{mg}$ per each levodopa administration for 4 weeks

\section{FOG (FOGQ) and depression improved}

Unknown

Co-administration of L-DOPS and entacapone improved FOG, yet entacapone or L-DOPS alone didn't, and the improvement was found only in levodopa-resistant FOG (visual analogue scale, VAS)

L-DOPS initially $100 \mathrm{mg} /$ day with a weekly increase of $100 \mathrm{mg}$ up to 600-900 mg/day maintenance

FOG improved in more than half 14 patients with "On and Off FOG"; 2 patients with "Off" FOG of patients (walk $10 \mathrm{~m}$ and return, subjective assessment) 
Table 3 Clinical trials of drug treatments for freezing of gait in Parkinson's disease (Continued)

\begin{tabular}{|c|c|c|c|c|c|}
\hline $\begin{array}{l}\text { Study } \\
\text { reference }\end{array}$ & Participants & Study design & Treatment & Main findings & FOG subtype \\
\hline & & & (range, 6-66 months). & & \\
\hline$[84]$ & $\begin{array}{l}42 \text { PD with } \\
\text { FOG }\end{array}$ & $\begin{array}{l}\text { Double-blind, randomized, } \\
\text { placebo-controlled }\end{array}$ & $\begin{array}{l}200 \mathrm{mg} / 500 \mathrm{~mL} \text { normal saline } \\
\text { twice a day for } 5 \text { days. }\end{array}$ & No improvement (FOGQ) & $\begin{array}{l}50 \% \text { patients } \\
\text { with FOG at } \\
\text { "On" state }\end{array}$ \\
\hline$[85]$ & $\begin{array}{l}15 \text { patients } \\
\text { with FOG } \\
\text { including } 6 \text { PD }\end{array}$ & $\begin{array}{l}\text { Prospective, open label, } \\
\text { uncontrolled }\end{array}$ & $\begin{array}{l}200 \mathrm{mg} \text { in } 500 \mathrm{~cm} 3 \text { of saline } \\
\text { solution given over a 3-h period, } \\
\text { twice a day for } 2 \text { days }\end{array}$ & $\begin{array}{l}\text { Improvement in PD patients } \\
\text { (FOGQ) }\end{array}$ & Resistant \\
\hline$[86]$ & $\begin{array}{l}10 \text { PD with } \\
\text { FOG }\end{array}$ & $\begin{array}{l}\text { Randomized double-blind } \\
\text { placebo-controlled, crossover }\end{array}$ & $\begin{array}{l}\text { Placebo (normal saline) or } \\
\text { amantadine ( } 400 \mathrm{mg} / \text { day) were } \\
\text { injected four times for } 2 \text { days, } 52-\mathrm{h} \\
\text { washout, then switched. }\end{array}$ & $\begin{array}{l}\text { No improvement (FOGQ, UPDRS, } \\
4 \times 10 \mathrm{~m} \text { walking test) }\end{array}$ & Resistant \\
\hline
\end{tabular}

\section{Atomoxetine}

5 PD with FOG

Prospective, double-blind, randomized, placebo-controlled

10 PD with Prospective, open label,

[88] FOG
$10 \mathrm{mg}$ daily and $10 \mathrm{mg}$

increments up to $40 \mathrm{mg}$ per day over 3 weeks.

$40 \mathrm{mg}$ daily for 2 weeks then increased to $40 \mathrm{mg}$ twice daily for 4-week then reduced to $40 \mathrm{mg}$ daily for 1 week

\section{Acetylcholinesterase inhibitor}

41 PD with

Open label, randomized,

[89] dementia controlled

130 PD

[90]

\section{Botulinum toxin}

$\begin{array}{lll}\text { [91] advanced } & \text { Randomized double blind } \\ \text { PD with FOG } & \text { placebo-controlled } \\ \text { 12 PD with } & \text { Randomized double-blind } \\ \text { [92] } & \text { FOG } & \text { placebo-controlled, crossover }\end{array}$

[93] including 7 PD

Prospective, open label, uncontrolled

Randomized, double-blind, placebo-controlled

Galantamine $4 \mathrm{mg}$ twice daily for the first 4 weeks, and then $8 \mathrm{mg}$ twice daily to the end of the 24 week trial period.

Rivastigmine was uptitrated from $3 \mathrm{mg}$ per day to the target dose of $12 \mathrm{mg}$ per day over 12 weeks

BTX-A injection into each leg's calf muscles, $150 \mathrm{IU}$ per leg

BTX-A injection into calf muscles, 16.25 to $25 \mathrm{U} /$ site, six injection sites per leg, 12-week washout, then switched

BTX-A injection into calf muscles, 3-6 sites per leg, 100-300 IU per session

BTX-A injection into tensor fasciae latae muscle, $50 \mathrm{U}$ per leg

$$
\text { uncontrolled }
$$
with FOG and 10 PD without FOG

14 PD with [95] FOG
Double-blind, placebocontrolled, randomized
BTX-B injection into calf muscles of the predominantly affected leg
No improvement (7 M Step test, FOGQ, Clinician's Global Index of Change (CGIC), Gait and Balance Scale)

No improvement (FOGQ)

Resistant

FOG improved (UPDRS freezing Unknown subitem)

FOG did not improve (episodes of FOG in the past month; NFOGQ)

No improvement (FOGQ, CGIC, UPDRS)

No improvement (FOGQ, diaries, TUG and "2-min walk test")

FOG improved (CGIC)

3 patients with "Off" FOG; 2 with "On" FOG; 2 with "On and Off" FOG

Resistant

FOG improved (FOGQ) in freezing, $5000 \mathrm{U}$
No improvement (UPDRS, VAS, Resistant and Modified Webster StepSeconds test)

A total of 39 clinical trials were summarized. The number of participants and their FOG subtype, the type of study design, drug treatments strategies, assessment methods for FOG and main findings were provided in this table

FOG Freezing of gait, PD Parkinson's disease, LCIG Levodopa-carbidopa intestinal gel, FOGQ Freezing of Gait-Questionnaire, NFOGQ New Freezing of Gait Questionnaire, UPDRS Unified Parkinson's Disease Rating Scale, PIGD Postural instability/gait difficulty, MPH Methylphenidate, L-DOPS L-threo-3, 4dihydroxyphenylserine, VAS Visual Analog Scale, CGIC Clinician's Global Index of Change

levodopa-resistance FOG $[56,66]$. One study including 5 PD with levodopa-resistance FOG who were treated with $24 \mathrm{~h}$ LCIG therapy for 6 months, and results showed median $360^{\circ}$ turn time, fall frequency and FOGQ improved [66]. The other was a single section study including 7 PD with FOG. Evaluations were performed in "On" 
state either during oral levodopa (60-90 min after intake of usual morning levodopa dose) or LCIG (60-90 min after starting LCIG infusion). UPDRS item 14 freezing significantly improved with LCIG in all patients compared to oral levodopa $(P=0.026)$. FOGQ also significantly improved with LCIG (oral levodopa:19.1 \pm 1.4 , LCIG:10.4 $\pm 1.6, P=0.017$ ) [56]. There are several potential explanations for the beneficial effect of LCIG on levodopa-resistant FOG. First, LCIG is administered via the jejunum, which provides greater bioavailability of levodopa compared with oral administration. This may enable better absorption and more levodopa in the brain than administration of levodopa via the oral route. Second, continuous delivery of LCIG provides stable plasma levodopa concentrations and avoids the pulsatile dopamine stimulation in striatum by oral levodopa. Additionally, LCIG can also be delivered at night. Adding nocturnal LCIG infusion improves sleep and better sleep quality improves daytime motor functions including FOG $[56,66]$.

\section{Dopamine agonists (DA)}

An open-label uncontrolled study evaluated transdermal patch rotigotine as monotherapy in untreated PD patients for 6 months and found that transdermal patch rotigotine improved all aspects of gait compared to baseline, including straight walking, gait initiation and turning [100]. Studies of DA as an adjunct to levodopa also found beneficial effects on gait speed in add-on therapy of apomorphine (sublingual) and pramipexole compared to levodopa alone $[101,102]$. An open label study found 3 months pramipexole treatment as an add-on to levodopa or single administration, FOGQ was significantly improved from $5.4 \pm 5.3$ to $4.2 \pm 4.1$ in $36 \mathrm{PD}$ patients [67]. Another open label study compared effects of transdermal patch of rotigotine, pramipexole LA and ropinirole $\mathrm{CR}$ on FOG, and showed that transdermal patch of rotigotine treatment for 2 months significantly improve FOG [68]. In this study, 47 patients (24 patients with FOG, 51\%) were treated with rotigotine (maintenance doses of 9-27 mg/day), 33 patients (16 patients with FOG, $48 \%$ ) received pramipexole LA (1.5-4.5 mg/day) and 31 patients (14 patients with FOG, 45\%) received ropinirole CR (8-16 mg/day). The FOGQ score was recorded during off time in patients with wearing off. FOGQ score were significantly decreased from $30.1 \pm 1.8$ at baseline to $21.0 \pm 1.2$ after 2 months rotigotine treatment, whereas pramipexole LA and ropinirole treatment did not alter FOGQ score compared to baseline. Such amelioration of FOG did not depend on reduction of off time after treatment, as off time improvements were similar among these treatments. One possibility is that rotigotine has higher binding affinity to D1/D5 receptors compared to pramipexole and ropinirole. The distinct pharmacological profile and 24-h steady hemodynamics of rotigotine might play a role in the therapeutic mechanism of FOG in PD patients with wearing off. Although subcutaneous continuous apomorphine infusion providing continuous dopaminergic stimulation similar to LCIG, the results of a clinical trial were disappointing [69]. Both the rotigotine transdermal patch and continuous apomorphine infusion are more convenient and reversible than LCIG; therefore, future research is needed to clarify whether they have beneficial effects on refractory FOG.

\section{Monoamine oxidase $B$ inhibitors (MAO-B inhibitor)}

Clinical trials have shown that selegiline was associated with reduced risk of future FOG [20, 103]. Lijima et al. used wearable sensors to record the daily walking profiles of 14 PD patients before and after selegiline add-on therapy, and used FOGQ to evaluate their FOG. Results revealed that FOGQ and UPDRSIII significantly improved after 3 months selegiline add-on or selegiline dose-increasing therapy (FOGQ, $9.2 \pm 4.9$ vs $7.9 \pm 5.1, P=0.01$; UPDRSIII $18.1 \pm 9.0$ vs. $13.1 \pm$ 10.0, $P<0.005)$. Hypokinesia index was also achieved by a small device that attached to the waist of the patients that measured three dimensionally the accelerations accompanied by limb and trunk movements and accelerations during gait. The results showed that improvements in hypokinesia and gait disorders did not occur in parallel. They suggested the beneficial effect was due to selegiline increased the synthesis of phenylamine, which might facilitate the release of noradrenaline. Hypokinesia of limb and trunk movements were not improved in this study indicating the beneficial effect exerted by selegiline add-on therapy was not by dopaminergic pathway [70]. Rasagiline, as an effective monotherapy in early PD and add-on therapy in PD patients with motor fluctuations [71, 104-106], has also been studied on FOG. In the LARGO study [71], a prospective, double-blind, randomized, placebo-controlled study enrolled 687 PD patients, in which 278 patients had FOG. Oral rasagiline $(1 \mathrm{mg}$ once daily) provided a significant improvement in UPDRS-PIGD $(P=0.034)$ and UPDRS-freezing scores $(P=0.045)$. In addition, in an open-label, multicenter study, 42 patients with FOG were treated with $1 \mathrm{mg}$ rasagiline daily as an add-on therapy, and FOGQ was assessed as primary outcome [72]. Results showed that patients treated with rasagiline had a statistically significant decrease in FOGQ score after 1, 2 and 3 months of therapy. However, the proportion of levodopaunresponsive FOG in these studies was unclear. Only one study investigated the effect of MAO-B inhibitor on levodopa unresponsive FOG. This study found that 6 of 14 PD patients with intractable FOG showed reduction in FOG number and duration after a 90-day course of $1 \mathrm{mg}$ daily rasagiline add-on therapy [73].

\section{Methylphenidate (MPH)}

MPH influences both the dopaminergic and norepinephrine systems and thus is supposed to play a positive role 
in FOG treatment. One multicenter, parallel, doubleblind, placebo-controlled, randomized study enrolled 69 PD patients who had severe gait disorders and FOG despite receiving an optimized, stable dose of levodopa and subthalamic nucleus (STN) stimulation. The results showed that $\mathrm{MPH}(1 \mathrm{mg} / \mathrm{kg}$ per day) treatment for 90 days was effective on levodopa-resistant FOG. In this study, FOG was assessed by FOGQ and the number of freezing episodes while taking walking trajectory [74]. Another study including17 advanced PD patients who presented gait disorders, despite their use of optimal dopaminergic doses and STN stimulation also showed that a daily dose of $1 \mathrm{mg} / \mathrm{kg}$ of MPH for 3 months significantly improved gait in the absence of levodopa as assessed by the walking speed, the number of steps and the number of freezing episodes [75]. Besides, one study tested the immediate effect of low dose MPH on five advanced $\mathrm{PD}$ and found the beneficial effect of MPH on FOG. The patients were tested during "off" state before and $2 \mathrm{~h}$ after the intake of $10 \mathrm{mg} \mathrm{MPH}$ while walking an "8 trajectory". The total walking time, total freezing time, number of freezing episodes and the non-freezing walking time were assessed and all these parameters were improved [76]. But the result of another 6-month placebo-controlled, double-blind, crossover study was disappointing [77]. Twenty-seven subjects with PD and moderate gait impairment were randomly assigned to MPH (maximum, up to $80 \mathrm{mg} /$ day) or placebo for 12 weeks and crossed over after a 3-week washout. Results showed MPH did not improve FOG as assessed by FOGQ and the freezing diary. Further well-designed studies were needed to explore the effectiveness of MPH on FOG.

\section{Istradefylline}

Caffeine, which is an adenosine receptor antagonist, has been shown to be effective for the treatment of FOG [107]. Istradefylline is a selective adenosine A2A receptor antagonist, which has also been found to be useful in reducing "off" time in PD [108], thus be tested for FOG therapy. Fourteen PD patients were treated with $20 \mathrm{mg}$ of Istradefylline in the morning. FOGQ scores were significantly decreased 1 month after Istradefylline treatment $(9.79 \pm 7.16)$ when compared to those before the intervention $(12.14 \pm 5.82, P=0.030)$ [78]. Recently, Mutsumi Iijima et al. conducted a multicenter, open-label, prospective interventional study which evaluated changes in total gait-related scores of the MDS-UPDRS II/III, FOGQ and NFOGQ in 31 PD patients treated with istradefylline. Patients with advanced PD who were treated with levodopa preparations and had wearing-off symptoms and gait disorders complicated with FOG were enrolled. Istradefylline was orally administrated for 12 weeks at $20 \mathrm{mg} /$ day for the first 4 weeks, followed by $20 \mathrm{mg} /$ day or an increased dose of $40 \mathrm{mg} /$ day for 8 weeks. Istradefylline significantly improved MDS-UPDRS Part III (ON-state) gait-related items total score after 12 weeks treatment compared with baseline $(-1.1 \pm 2.0, P=0.007)$, FOGQ $(-2.0 \pm 3.1, P=0.002)$, and NFOGQ $(-2.2 \pm 5.1, P=0.026)$ [79]. Istradefylline showed promising in treating FOG, but further studies involving larger patient numbers and randomized, controlled design are needed.

\section{Antidepressants}

Depression is found to be a risk factor for FOG development and limbic system has been proven to be involved in FOG pathophysiology, which were discussed previously. However, only one study has studied the effect of antidepressants on FOG therapy. This prospective, multicenter, open-label, randomized study assigned PD patients with mild to severe depression into selective serotonin reuptake inhibitors (SSRIs) (paroxetine or escitalopram, 27 enrolled, 25 analyzed) or serotonin and norepinephrine reuptake inhibitors (SNRIs) (duloxetine, 28 enrolled, 27 analyzed) group. The mean changes (from baseline) of FOGQ scores at 6 and 10 weeks were statistically significant in both the SSRI (6 weeks, -2.2 , $P=0.018 ; 10$ weeks, $-2.9, P=0.012$ ) and SNRI (6 weeks, $-2.1, P=0.047$; 10 weeks, $-3.4, P=0.010$ ) groups [80], indicating that FOG was significantly improved. No significant differences were observed between the SSRI and SNRI groups. Depression symptom was also improved. Further studies are needed to evaluate the effects of antidepressants on FOG.

\section{L-threo-3, 4-dihydroxyphenylserine ((L-DOPS, droxidopa)}

One open label, controlled study randomized 16 PD patients with FOG into L-DOPS co-administered with entacapone group $(n=6)$, entacapone alone group $(n=$ $5)$, and L-DOPS alone group $(n=5)$ in addition to their original medication. Results showed that the combination of L-DOPS and entacapone as an add-on therapy significantly improved FOG based on the visual analogue scale at 4 weeks compared with baseline while L-DOPS alone did not. The improvement was observed only in levodopa-resistant FOG patients, suggesting that dysfunction of noradrenergic neurons plays a significant role in levodopa-resistant FOG [81]. A prospective, open label, noncontrolled study including 13 PD with FOG, found that L-DOPS initially $100 \mathrm{mg} /$ day with a weekly increase of $100 \mathrm{mg}$ up to $600-900 \mathrm{mg} /$ day maintenance, FOG improved in half of patients [82].

\section{Amantadine}

A retrospective study reviewed PD patients who received amantadine specifically for FOG and found that 10 of 11 patients reported subjective improvement in FOG after initiating amantadine. Median amantadine dosage was 
$100 \mathrm{mg}$ twice daily, and treatment duration was 20 months (range 6-66 months). Four patients reported reduction in benefit after 4 months, indicating that this effect may be transient [83]. Although the mechanism of amantadine in PD is unclear, dopaminergic and nondopaminergic mechanisms are both involved. Additionally, the effect of intravenous amantadine on FOG has been explored, and the results were inconsistent [8486]. In Kim et al's open label study, $6 \mathrm{PD}$ patients with intractable freezing was administrated with intravenous amantadine $\left(200 \mathrm{mg}\right.$ in $500 \mathrm{~cm}^{3}$ of saline solution given over a 3 -h period), twice a day for 2 days along with the pre-existing anti-parkinsonism medication. Results showed a marked improvement on FOG (FOGQ score $\leq$ -4) in 5 of $6 \mathrm{PD}$ patients [85]. However, two doubleblind, randomized, placebo-controlled studies including 42 PD and 10 PD patients with FOG respectively found that intravenous amantadine had no beneficial effect on FOG $[84,86]$.

\section{Atomoxetine}

Atomoxetine is a selective norepinephrine reuptake inhibitor that enhances noradrenergic transmission, thus it is supposed to be effective for FOG. However, a randomized double-blind, placebo-controlled study enrolled 5 patients did not find its efficiency on FOG [87]. Another eight-week open label study enrolled 10 PD patients with dopamine-unresponsive FOG also failed to demonstrate its efficiency [88].

\section{Acetylcholinesterase inhibitor}

An underlying loss of cholinergic function contributes to freezing [109], thus the effect of acetylcholinesterase inhibitors on FOG has been tested. One open controlled study included 41 patients with PD with dementia and randomized patients to a galantamine treatment group in which patients received galantamine in addition to ongoing treatment (21 patients) and a control group (20 patients) who continued ongoing treatment. Results showed 24-week galantamine (8 mg twice daily) add-on therapy significantly improved freezing assessed by UPDRS freezing subitem $(3.0 \pm 0.5$ to $2.3 \pm 0.4, P=0.03)$ [89]. But recently the double blind placebo-controlled study did not find FOG improvement after acetylcholinesterase inhibitor rivastigmine treatment [90].

\section{Botulinum toxin (BTX)}

Two double blind placebo-controlled studies using subjective and objective measures found no significant FOG improvement with BTX-A injections into calf muscles [91, 92], albeit the beneficial effect has been observed previously in two open label studies [93, 94]. Apart from BTX-A, the effect of BTX-B on FOG was also disappointing [95], thus this approach is therefore discouraged.

\section{Summary of pharmacological treatments for FOG}

In this section, a total of 39 clinical trials were included in this review, but high quality RCT studies were rare. Meanwhile, there was no meta-analysis in this field. Despite the limited effectiveness of current medications for FOG, there were still some clinical studies that showed promise for some drugs. Levodopa is the first choice for FOG treatment in PD $[3,55,59]$. Besides, a total of eight studies containing both retrospective and prospective open-label studies all found that LCIG improved FOG significantly [56, 60-66]. LCIG is an invasive approach, which limits its clinical application to some extent. One prospective, open label, controlled study showed transdermal patch of rotigotine treatment significantly improved FOG [68]. This promising result needs to be examined by further studies. One open-label study supported selegiline and one double-blind, RCT study and one open-label study supported rasagiline as add-on treatments for FOG [70-72]. One multicenter, parallel, double-blind, placebo-controlled, randomized study found that MPH improved levodopa-resistant FOG in those patients who has already received an optimized, stable dose of levodopa and STN stimulation [74, 75]. Therefore, for PD patients who had received STN-Deep brain stimulation (DBS) but still with FOG, $1 \mathrm{mg} / \mathrm{kg} /$ day MPH could be tried. Recently, two pilot open-label studies showed Istradefylline was effective on FOG treatment [78, 79], and one prospective, open label, randomized, controlled, multicenter study found SSRIs (paroxetine or escitalopram) or SNRIs (duloxetine) improved FOG significantly [80].

Continuous subcutaneous apomorphine infusion is reversible and more convenient than LCIG, but the result of one small study was disappointing. The efficiency of subcutaneous apomorphine infusion on FOG needs to be tested in future studies. It is worth noting that several studies supported that the DA increased the risk for FOG [32, 55, 57], physicians should take caution while prescribing DA for PD patients with FOG. There was lack of strong evidence that oral amantadine can improve FOG and two double-blind, randomized, placebocontrolled studies found that intravenous amantadine had no beneficial effect on FOG $[84,86]$. L-DOPS plus entacapone were shown to be effective in improving FOG, but whether L-DOPS alone could improve FOG needed further studies [81, 82]. An underlying loss of cholinergic function contributes to freezing, but the recently double blind placebo-controlled study did not find FOG improvement after acetylcholinesterase inhibitor rivastigmine treatment [90], although a previous open label controlled study showed positive results under 
another acetylcholinesterase inhibitor galantamine treatment. Botulinum toxin and Atomoxetine are ineffective according to the clinical evidence.

Despite some treatments showed promising results, it is still difficult to treat FOG in PD, especially those levodopa resistant FOG. We cannot conclude one drug was effective based on limited clinical trials without metaanalysis or high quality RCTs. Similarly, we cannot deny one because of limited studies that have not shown the effectiveness. Future multicenter, large sample, RCT studies are needed to test the effects of these drugs, especially the promising ones.

\section{Non-pharmacological therapy}

\section{Spinal cord stimulation (SCS)}

Recently, one open-label, nonrandomized pilot study investigated the safety and efficacy of SCS on gait in 4 patients with advanced PD previously treated with STNDBS. Paddle electrodes with 3 columns of contacts were implanted in the epidural space of the upper thoracic spine (T2-T4). Results showed $300 \mathrm{~Hz} / 90$ us SCS induced a significant improvement in gait and FOG. FOGQ improved from $17.8 \pm 0.9$ at baseline to $7.8 \pm 0.9$ at 6months $(P<0.001)$ [110]. The beneficial effect of SCS was also found in another open-label, nonrandomized pilot study, 5 PD participants with significant gait disturbances and FOG despite optimization of dopaminergic medication underwent mid-thoracic SCS (T8-T10, 300$400 \mathrm{us} / 30-130 \mathrm{~Hz}$ ). Four of the five participants reported FOG occurred less frequently [111]. The mechanisms involved in SCS modulating gaits are unclear. It has been reported that SCS may influence neuronal firing in SMA, a key hub for controlling gait initiation $[112,113]$. Another theory said that SCS might disrupt the aberrant inhibition of the globus pallidus internus onto thalamus and SMA [114, 115]. Anticipatory postural adjustment (APA) is required in advance of each step forward for normal gait. During freezing episodes, the intention to walk is uncoupled from the triggering of APA, and then consequent failure of the forward movement happened. SCS improved APA [116] and APA is found to be modulated by SMA [112], thus it has been supposed that SCS improved FOG probably by modulating SMA to improve APA and facilitate gait initiation [117].

\section{Deep brain stimulation (DBS)}

\section{STN-DBS high frequency stimulation (HFS)}

A meta-analysis summarized the short and long-term effects of bilateral STN-DBS with HFS (usually $130 \mathrm{~Hz}$ ) on gait and FOG in PD [118]. Seven studies with available data of FOG (UPDRS item 2.14) were included [119125]. The results showed that gait and FOG could be improved for more than 4 years in the Med-Off/StimOn condition. However, no beneficial effect was found for the Med-On/Stim-On compared with Med-ON/ Stim-Off. This is probably due to the selection criteria for DBS candidates was levodopa responsiveness of global motor performance as well as gaits. These results confirmed the lack of a synergistic effect of medication and DBS [118]. Other studies also reported that STNHFS improved FOG in most patients [126-128]. However, STN-DBS worsened or induced the new appearance of FOG and/or gait akinesia during the immediate postoperative period in some patients $[129,130]$. Such paradoxical deterioration of gait and akinesia is rare, and this side effect is probably related to misplaced contacts [131]. Therefore, when levodopa-responsive FOG patients is complicated by dose related side effects of levodopa treatment, high frequency STN-DBS can be considered. Meanwhile, antidepressant treatment can be tried if depression exists, as depression may negatively affect the outcome of HFS on FOG [132].

\section{STN-DBS low frequency stimulation (LFS)}

LFS (most commonly $60 \mathrm{~Hz}$ ) STN-DBS has been tried to treat PD patients with FOG and have shown its shortterm or even long-term beneficial effects on improving FOG and other axial symptoms compared with HFS [133-135], although some studies argued that there was no significant difference between HFS and LFS for controlling FOG $[136,137]$. Currently, there are lack of metaanalysis to examine efficiency of low frequency STN-DBS on FOG, thus caution should be used in interpreting the results of these clinical studies and drawing conclusions. However, LFS should be recommended in STN-DBS patients with refractory axial symptoms (particularly FOG) at HFS, as long as tremor doesn't worsen significantly with LFS [138-140].

\section{PPN-DBS}

One randomized double-blinded study evaluated the long-term effect of PPN-DBS with a follow-up period for 24-48 months and reported that the benefits on FOG and falls lasted at least 4 years in four of the six patients [141]. On behalf of the Movement Disorders Society PPN-DBS Working Group, Thevathasan et al. reviewed the literature from 1990 to 2017 comprising fewer than 100 cases and summarized the outcomes of PPN-DBS application in patients with PD [142]. Although firm conclusions cannot be drawn on therapeutic efficacy, the literature suggested that PPN-DBS could improve medication refractory gait freezing and falls [143-148]. These cases were from different surgical centers; therefore, there was great variability in clinical methodology. Caudal or rostral PPN, unilateral or bilateral implantation, high or low frequency stimulation are factors that may affect the outcome. Thus, consensus about the optimal methodology is needed. 


\section{Dual-site DBS}

A crossover, double-blind, randomized controlled trial enrolled 12 PD patients with gait and balance impairment resistant to optimized dopaminergic and STN-DBS treatment found that combined stimulation of the STN and substantia nigra pars reticulata $(\mathrm{SNr})$ using interleaved stimulation of both sites at a high frequency of $125 \mathrm{~Hz}$ improved FOG at 3-month follow-up [149]. In another randomized, crossover pilot study, Valldeoriola and colleagues modified this approach by co-stimulating STN and SNr at different frequencies in 6 patients, and investigated the effects on FOG and other PD motor symptoms [150]. The results suggested that combined HFS-STN and LFS-SNr stimulation had the best effect on various measures of FOG, compared to stimulation of a single target alone. However, no comparative data between low- and high-frequency $\mathrm{SNr}$ stimulation (neither $\mathrm{SNr}$ alone nor combined with STN) is available, whether a low frequency at $\mathrm{SNr}$ would be superior over high frequency remains unclear.

\section{Noninvasive vagus nerve stimulation (VNS)}

Recently, it has been reported that VNS administered for 10 days improved locomotion in a rodent model of PD [151]. Thus, an observational, open-label, pilot study explored the effect of single-dose, noninvasive VNS on gait pattern and FOG in 12 patients with FOG. A total of 2 VNS treatments were applied to the left vagus nerve in left side of the neck below the mandibular angle, medial to the sternocleidomastoid muscle and lateral to the larynx, with an interval of $15 \mathrm{~min}$ between 2 VNS treatments. Each VNS treatment consisted of $120 \mathrm{~s}$ of stimulation. Assessments were performed just before and $15 \mathrm{~min}$ after the application of VNS. Video analysis showed that VNS significantly improved the number of steps taken while turning [152]. The mechanism was still unknown. One possibility is that locus coeruleus noradrenergic neurons degenerate prior to substantia nigra dopaminergic neurons in PD, and VNS may activate locus coeruleus neurons [151]. A multicenter, doubleblind, placebo/sham-controlled randomized trial of noninvasive VNS in patients with PD are needed.

\section{Transcranial magnetic stimulation (TMS)}

TMS induces electrical current generated through a rapidly changed magnetic field and activates cortical neurons located up to $2-3 \mathrm{~cm}$ beneath the scalp. Recently, one meta-analysis enrolled 7 RCTs including 102 participants, where 6 studies using repetitive TMS (rTMS) and one using dual-mode and dual-site (rTMS + tanscranial direct current stimulation (tDCS)). Results showed that rTMS had a beneficial effect on FOG in PD patients assessed by FOGQ and turning time. However, subgroup analysis according to stimulation site showed neither motor cortex stimulation nor frontal cortex stimulation had beneficial effect on FOG [153]. Other stimulation site has also been explored. One recent RCT including $30 \mathrm{PD}$ patients with FOG showed that 10 sessions of highfrequency $(10 \mathrm{~Hz})$ rTMS over the SMA had beneficial effects on FOG in PD patients [154]. This study also found that the beneficial effects could last at least 4 weeks after stimulation. This result was consistent with Kim's results, where Kim et al. [155] reported significant improvements after 2 sessions of high-frequency SMA stimulation in 12 PD patients, but not after motor cortex stimulation. These results suggested that SMA stimulation may be a moreappropriate target in PD patients with FOG, which need to be confirmed by future studies.

\section{Transcranial direct current stimulation (tDCS)}

In general, anodal tDCS facilitates cortical excitability. In a crossover, double-blind, randomized, sham-controlled study including $10 \mathrm{PD}$ patients with levodopa-resistant FOG, five sessions of $2 \mathrm{~mA}$ anodal tDCS on primary motor cortex showed benefits on FOG and motor performance after tDCS [156]. However, another crossover double-blind, randomized, sham-controlled study applied one session multibipolar tDCS electrodes stimulating only primary motor cortex in PD patients with FOG didn't improve FOG. But after stimulating both primary motor cortex and left dorsolateral prefrontal cortex, the performance in gait-provoking test, stroop, and time up and go tests were improved [157]. Besides, another double-blinded crossover randomized, sham-controlled study including 10 PD with FOG showed a single dose of anodal tDCS over the SMAs did not improve selfinitiated gait in PD and FOG [158].

\section{Physiotherapy}

Cues are the most well-known and widely studied behavioral approaches for ameliorating FOG. Cue is defined as using external temporal or spatial stimuli to facilitate movement (gait) initiation and continuation [159]. Cues are classified into visual, auditory or somatosensory cue based on delivery modality classification. The remarkable responsiveness of PD patients to external cues has inspired several recent studies to evaluate the potential of technology-based wearable systems for improving FOG. For example, laser-shoe, a new form of continuous ambulatory cue has been developed recently. The laser-shoe is equipped with a line-generating laser activated through the loading of the body weight onto the switch upon heel contact during the gait cycle. The laser line appears orthogonally in front of the patient's contralateral foot. Thus the cues are tuned exactly to the step frequency of the patient. A total of 21 patients with PD and FOG were tested in a controlled gait laboratory, both "off" and "on" medication. Cueing using laser shoes 
was associated with a significant reduction in the number and duration of FOG episodes, both "off" and "on" medication [160]. Besides, in McCandless et al's study, rhythmic tactile stimulation (pulsed vibration) was provided at an adjustable tempo of 10 to 280 beats/minute via a vibration clip attached anteriorly over the right side of the user's pelvis [161]. Results showed an immediate positive effect on the mean percentage of Off-FOG episodes during the walking task in 20 PD patients. In Zhao et al' s study [162], they used Google glass to provide three audiovisual cues: bone-conduction allowed users to hear the rhythmic auditory sound through vibrations of Google Glass; flashing light (LED) caused the screen to rhythmically flash on and off; the optic flow generated vertically oriented lines on both sides of the screen that moved forward at a fixed speed. Zhao et al. carried out measurements on 12 participants and observed a significant immediate effect of auditory cueing on the mean frequency of FOG episodes during walking tasks with $360^{\circ}$ turn. Nine of 12 participants were willing to use Google Glass at home to address FOG. Recently, Sweeney et al. reviewed wearable cueing devices delivering visual, auditory or vibration cue and addressing FOG in PD in recent years, and found that cueing was generally effective and promising [163]. However, it should be noted that some devices although seems promising, efficacy of various cueing devices need to be further tested outside the home or laboratory and in a larger PD patients with FOG.

Apart from cues, treadmill training [164-168], obstacle aquatic training [169], supervised slackline training [170], walk-bicycle [171], and action observation [172, 173] have also shown positive effects on FOG. Recently, Cosentino $\mathrm{C}$ et al. [174] performed a systematic review and metaanalysis to evaluate the effectiveness of physiotherapy intervention on FOG symptoms. A total of 19 studies, including 913 patients, were enrolled and FOGQ was used as the primary outcome measure. This review provides evidence for short-term effectiveness of physiotherapy in improving FOG compared with no treatment (effect size = $-0.28[-0.45,-0.11], P=0.001$ ) or usual care (effect size $=0.43[-0.65,-0.21], P<0.0001)$. These results seem to be maintained at the follow-up examinations (effect size $=-0.52[-0.78,-0.26] ; \quad P=0.001)$. Furthermore, among these various interventions, action observation, treadmill combined with cueing, and prolonged homebased exercise trainings are able to impact on FOG more than other approaches.

\section{Summary of non-pharmacological treatments for FOG}

In this section, invasive stimulation including DBS and SCS, noninvasive brain stimulations including tDCS, rTMS, noninvasive VNS, and physiotherapy including cues and other training strategies have been reviewed and summarized. A meta-analysis containing 7 studies revealed that HFS STN-DBS improved Med-off gait and FOG, and this beneficial effect could maintain for more than 4 years [118]. Although there was lack of strong evident that LFS STN-DBS could improve FOG, some literature suggested that LFS should be recommended in STN-DBS patients with refractory axial symptoms (particularly FOG) as long as tremor did not worsen significantly with LFS [138-140]. PPN was a new promising target for DBS to address FOG in recent years. Thevathasan et al. reviewed the literature from 1990 to 2017 and suggested that PPN-DBS could alleviate medication refractory gait freezing and falls [142]. In addition, small sample pilot studies showed SCS [110,111] and dual site DBS such as combined stimulation of the STN and $\mathrm{SNr}$ $[149,150]$ significantly improved FOG. These promising results need to be examined by further RCT studies in a larger sample. Of noninvasive brain stimulation, tDCS and rTMS have been examined for FOG treatment in PD. Pilot studies showed that SMA may be a moreappropriate target for rTMS in PD patients with FOG $[154,155]$. Besides, one recent study showed that VNS significantly improved FOG in 12 PD patients [152]. Multicenter, double-blind, placebo/sham-controlled randomized trials are needed to confirm theses exciting and promising findings. Of physiotherapy, wearable cueing devices was generally effective and promising [163]. However, the efficacy of various cueing devices need to be further tested outside the home or laboratory and in a larger PD patients with FOG. Apart from cues, a systematic review and meta-analysis found that action observation, treadmill combined with cueing, and prolonged homebased exercise trainings were able to impact on FOG more than other approaches [174].

\section{Conclusions}

FOG is a common, disabling symptom of PD, affecting patients' independence and quality of life, and often contributing to wheelchair use and falls. Risk factors of FOG are crucial for screening FOG and are helpful to understand mechanism of FOG as well. Demographic information, motor symptoms, non-motor symptoms, neuroimaging, fluid parameters, and medication use were explored. Among them, gait disorders, PIGD phenotype, lower striatal DAT uptake were found to be independent risk factors of FOG with consistent evidence. Other risk factors with contradictory or limited evidence need to be tested in future studies. How to optimize the combination of these risk factors and further improve the accuracy of FOG prediction is an important problem to be solved. Several pharmacological treatments are available and effective in terms of reducing the number and duration of freezing episodes. Dopamine replacement therapy with 
levodopa is the first choice for FOG treatment in PD. LCIG showed beneficial effect on FOG with consistent findings, but it is an invasive approach, which limits its clinical application to some extent. Moreover, Istradefylline and rasagiline showed promising in treating FOG, but further studies involving larger patient numbers and randomized, controlled design are needed, especially for those levodopa resistant FOG. Recently, scientists have introduced some promising non-pharmacological treatments. Several novel therapeutic strategies seem to be effective, such as rTMS over SMA, dual-site DBS, SCS and VNS. Of physiotherapy, wearable cueing devices seem to be generally effective and promising, but efficacy of various cueing devices need to be further tested outside the home or laboratory and in a larger PD patients with FOG.

\begin{abstract}
Abbreviations
FOG: Freezing of gait; PD: Parkinson's disease; PPMI: Parkinson's Progression Markers Initiative; FOGQ: Freezing of Gait-Questionnaire; NFOGQ: New freezing of gait questionnaire; MDS-UPDRS: Movement Disorder SocietySponsored Revision of the Unified Parkinson's Disease Rating Scale; PIGD: Postural instability and gait difficulty; PMSF: Pontomedullary reticular formation; MLR: Mesencephalic locomotor region; PPN: Pedunculopontine nucleus; SMA: Supplementary motor area; PM: Premotor area; RBD: REM Sleep Behavior Disorder; RBDSQ: RBD screening questionnaire;

LEDD: Levodopa equivalent daily doses; DAT: Dopamine transporter; CSF: Cerebrospinal fluid; WMH: White matter hyperintensities; TD: Tremordominant; HR: Hazard ratio; OR: Odds ratio; ESS: Epworth Sleepiness Scale; LCIG: Levodopa-carbidopa intestinal gel; DA: Dopamine agonists; MAO-B inhibitor: Monoamine oxidase B inhibitors; MPH: Methylphenidate; L-DOPS: Lthreo-3, 4-dihydroxyphenylserine; SSRIs: Selective serotonin reuptake inhibitors; SNRIs: Serotonin and norepinephrine reuptake inhibitors; DATATOP: Deprenyl and tocopherol antioxidative therapy of parkinsonism; BTX: Botulinum toxin; STN: Subthalamic nucleus; SCS: Spinal cord stimulation; APA: Anticipatory postural adjustment; HFS: High frequency stimulation; LFS: Low frequency stimulation; DBS: Deep brain stimulation; VNS: Vagus nerve stimulation; TMS: Transcranial magnetic stimulation; tDCS: Transcranial direct current stimulation; SNr: Substantia nigra pars reticulata
\end{abstract}

\section{Acknowledgements}

Not applicable.

\section{Authors' contributions}

Chao Gao: Reviewing the literature, drafting and revising the manuscript; All other authors: critically revising the manuscript. All authors read and approved the final manuscript.

\section{Funding}

This work was supported by grants from the National Natural Science Foundation of China $(81430022,91332107,81371407,81971183)$ and Clinical Research Center, Shanghai Jiao Tong University School of Medicine(2017NKX001)

\section{Availability of data and materials}

All the data mentioned in this article are available on published article.

\section{Ethics approval and consent to participate}

Not applicable.

\section{Consent for publication}

Not applicable.

\section{Competing interests}

The authors declare that they have no competing interests.

\section{Author details}

${ }^{1}$ Department of Neurology, Ruijin Hospital Affiliated to Shanghai Jiao Tong University School of Medicine, Shanghai, China. ${ }^{2}$ Co-innovation Center of Neuroregeneration, Nantong University, Nantong, Jiangsu Province, China.

Received: 26 August 2019 Accepted: 24 March 2020

Published online: 15 April 2020

\section{References}

1. Giladi N, Nieuwboer A. Understanding and treating freezing of gait in parkinsonism, proposed working definition, and setting the stage. Mov Disord. 2008;23(Suppl 2):S423-5.

2. Bloem BR, Hausdorff JM, Visser JE, Giladi N. Falls and freezing of gait in Parkinson's disease: a review of two interconnected, episodic phenomena. Mov Disord. 2004;19(8):871-84.

3. Schaafsma JD, Balash Y, Gurevich T, Bartels AL, Hausdorff JM, Giladi N. Characterization of freezing of gait subtypes and the response of each to levodopa in Parkinson's disease. Eur J Neurol. 2003;10(4):391-8.

4. Okuma Y, Silva de Lima AL, Fukae J, Bloem BR, Snijders AH. A prospective study of falls in relation to freezing of gait and response fluctuations in Parkinson's disease. Parkinsonism Relat Disord. 2018;46:30-5.

5. Walton CC, Shine JM, Hall JM, O'Callaghan C, Mowszowski L, Gilat M, Szeto $J Y$, Naismith SL, Lewis SJ. The major impact of freezing of gait on quality of life in Parkinson's disease. J Neurol. 2015;262(1):108-15.

6. Nutt JG, Bloem BR, Giladi N, Hallett M, Horak FB, Nieuwboer A. Freezing of gait: moving forward on a mysterious clinical phenomenon. Lancet Neurol. 2011;10(8):734-44

7. Mori S. Integration of posture and locomotion in acute decerebrate cats and in awake, freely moving cats. Prog Neurobiol. 1987;28(2):161-95.

8. Snijders AH, Takakusaki K, Debu B, Lozano AM, Krishna V, Fasano A, Aziz TZ, Papa SM, Factor SA, Hallett M. Physiology of freezing of gait. Ann Neurol. 2016;80(5):644-59.

9. Brooks VB, Stoney SD Jr. Motor mechanisms: the role of the pyramidal system in motor control. Annu Rev Physiol. 1971;33:337-92.

10. Takakusaki K. Neurophysiology of gait: from the spinal cord to the frontal lobe. Mov Disord. 2013;28(11):1483-91.

11. Nieuwboer A, Giladi N. Characterizing freezing of gait in Parkinson's disease: models of an episodic phenomenon. Mov Disord. 2013;28(11):1509-19.

12. Plotnik M, Giladi N, Hausdorff JM. Is freezing of gait in Parkinson's disease a result of multiple gait impairments? Implications for treatment. Parkinsons Dis. 2012;2012:459321.

13. Lewis SJ, Barker RA. A pathophysiological model of freezing of gait in Parkinson's disease. Parkinsonism Relat Disord. 2009:15(5):333-8.

14. Vandenbossche J, Deroost N, Soetens E, Coomans D, Spildooren J, Vercruysse S, Nieuwboer A, Kerckhofs E. Freezing of gait in Parkinson's disease: disturbances in automaticity and control. Front Hum Neurosci. 2012;6:356.

15. Jacobs JV, Nutt JG, Carlson-Kuhta P, Stephens M, Horak FB. Knee trembling during freezing of gait represents multiple anticipatory postural adjustments. Exp Neurol. 2009;215(2):334-41.

16. Kim R, Lee J, Kim HJ, Kim A, Jang M, Jeon B, Kang UJ. CSF beta-amyloid42 and risk of freezing of gait in early Parkinson disease. Neurology. 2019;92(1): e40-7.

17. Kim R, Lee J, Kim Y, Kim A, Jang M, Kim HJ, Jeon B, Kang UJ, Fahn S. Presynaptic striatal dopaminergic depletion predicts the later development of freezing of gait in de novo Parkinson's disease: an analysis of the PPMI cohort. Parkinsonism Relat Disord. 2018;51:49-54.

18. Ehgoetz Martens KA, Lukasik EL, Georgiades MJ, Gilat M, Hall JM, Walton CC, Lewis SJG. Predicting the onset of freezing of gait: a longitudinal study. Mov Disord. 2018;33(1):128-35.

19. Herman T, Shema-Shiratzky S, Arie L, Giladi N, Hausdorff JM. Depressive symptoms may increase the risk of the future development of freezing of gait in patients with Parkinson's disease: findings from a 5-year prospective study. Parkinsonism Relat Disord. 2018;60:98-104.

20. Giladi N, McDermott MP, Fahn S, Przedborski S, Jankovic J, Stern M, Tanner C, Parkinson Study G. Freezing of gait in PD: prospective assessment in the DATATOP cohort. Neurology. 2001;56(12):1712-21.

21. Forsaa EB, Larsen JP, Wentzel-Larsen T, Alves G. A 12-year population-based study of freezing of gait in Parkinson's disease. Parkinsonism Relat Disord. 2015;21(3):254-8. 
22. Zhang $H$, Yin X, Ouyang Z, Chen J, Zhou S, Zhang C, Pan X, Wang S, Yang J, Feng $Y$, et al. A prospective study of freezing of gait with early Parkinson disease in Chinese patients. Medicine. 2016;95(26):e4056.

23. Ou R, Wei Q, Cao B, Song W, Hou Y, Liu H, Yuan X, Zhao B, Wu Y, Shang H. Predictors of freezing of gait in Chinese patients with Parkinson's disease. Brain Behav. 2018;8(3):e00931.

24. Banks SJ, Bayram E, Shan G, LaBelle DR, Bluett B. Non-motor predictors of freezing of gait in Parkinson's disease. Gait Posture. 2019;68:311-6.

25. Djaldetti R, Rigbi A, Greenbaum L, Reiner J, Lorberboym M. Can early dopamine transporter imaging serve as a predictor of Parkinson's disease progression and late motor complications? J Neurol Sci. 2018;390:255-60.

26. Chung SJ, Lee YH, Yoo HS, Oh JS, Kim JS, Ye BS, Sohn YH, Lee PH. White matter hyperintensities as a predictor of freezing of gait in Parkinson's disease. Parkinsonism Relat Disord. 2019:66:105-9.

27. Macht M, Kaussner Y, Moller JC, Stiasny-Kolster K, Eggert KM, Kruger HP, Ellgring $\mathrm{H}$. Predictors of freezing in Parkinson's disease: a survey of 6,620 patients. Mov Disord. 2007;22(7):953-6.

28. Shulman LM. Is there a connection between estrogen and Parkinson's disease? Parkinsonism Relat Disord. 2002;8(5):289-95.

29. Wilson RS, Yu L, Lamar M, Schneider JA, Boyle PA, Bennett DA. Education and cognitive reserve in old age. Neurology. 2019;92(10):e1041-50.

30. Perez-Lloret S, Negre-Pages L, Damier P, Delval A, Derkinderen P, Destee A, Meissner WG, Schelosky L, Tison F, Rascol O. Prevalence, determinants, and effect on quality of life of freezing of gait in Parkinson disease. JAMA Neurol. 2014;71(7):884-90.

31. Osaki $Y$, Morita $Y$, Miyamoto $Y$, Furuta $K$, Furuya $H$. Freezing of gait is an early clinical feature of progressive supranuclear palsy. Neurol Clin Neurosci. 2017;5(3):86-90.

32. Giladi N, Treves TA, Simon ES, Shabtai H, Orlov Y, Kandinov B, Paleacu D, Korczyn AD. Freezing of gait in patients with advanced Parkinson's disease. J Neural Transm (Vienna). 2001;108(1):53-61.

33. Giladi N, McMahon D, Przedborski S, Flaster E, Guillory S, Kostic V, Fahn S. Motor blocks in Parkinson's disease. Neurology. 1992:42(2):333-9.

34. Garcia-Ruiz PJ, Del Val J, Fernandez IM, Herranz A. What factors influence motor complications in Parkinson disease?: a 10-year prospective study. Clin Neuropharmacol. 2012;35(1):1-5.

35. Lewis SJ, Shine JM. The next step: a common neural mechanism for freezing of gait. Neuroscientist. 2016;22(1):72-82.

36. Magrinelli F, Picelli A, Tocco P, Federico A, Roncari L, Smania N, Zanette G, Tamburin S. Pathophysiology of motor dysfunction in Parkinson's disease as the rationale for drug treatment and rehabilitation. Parkinsons Dis. 2016: 2016:9832839.

37. Rosenberg-Katz K, Herman T, Jacob Y, Giladi N, Hendler T, Hausdorff JM. Gray matter atrophy distinguishes between Parkinson disease motor subtypes. Neurology. 2013;80(16):1476-84.

38. Zuo LJ, Piao YS, Li LX, Yu SY, Guo P, Hu Y, Lian TH, Wang RD, Yu QJ, Jin Z, et al. Phenotype of postural instability/gait difficulty in Parkinson disease: relevance to cognitive impairment and mechanism relating pathological proteins and neurotransmitters. Sci Rep. 2017;7:44872.

39. Obeso JA, Rodriguez-Oroz M, Marin C, Alonso F, Zamarbide I, Lanciego JL, Rodriguez-Diaz M. The origin of motor fluctuations in Parkinson's disease: importance of dopaminergic innervation and basal ganglia circuits. Neurology. 2004;62(1 Suppl 1):S17-30.

40. Schlenstedt C, Muthuraman M, Witt K, Weisser B, Fasano A, Deuschl G. Postural control and freezing of gait in Parkinson's disease. Parkinsonism Relat Disord. 2016;24:107-12.

41. Duncan RP, Leddy AL, Cavanaugh JT, Dibble LE, Ellis TD, Ford MP, Foreman KB, Earhart GM. Balance differences in people with Parkinson disease with and without freezing of gait. Gait Posture. 2015;42(3):306-9.

42. Morris ME, lansek R, Galna B. Gait festination and freezing in Parkinson's disease: pathogenesis and rehabilitation. Mov Disord. 2008;23(Suppl 2): S451-60.

43. Bekkers EMJ, Dijkstra BW, Heremans E, Verschueren SMP, Bloem BR, Nieuwboer A. Balancing between the two: are freezing of gait and postural instability in Parkinson's disease connected? Neurosci Biobehav Rev. 2018; 94:113-25.

44. Walton CC, Mowszowski L, Gilat M, Hall JM, O'Callaghan C, Muller AJ, Georgiades M, Szeto JYY, Ehgoetz Martens KA, Shine JM, et al. Cognitive training for freezing of gait in Parkinson's disease: a randomized controlled trial. NPJ Parkinsons Dis. 2018;4:15.
45. Ehgoetz Martens KA, Hall JM, Georgiades MJ, Gilat M, Walton CC, Matar E, Lewis SJG, Shine JM. The functional network signature of heterogeneity in freezing of gait. Brain. 2018;141(4):1145-60.

46. Alibiglou L, Videnovic A, Planetta PJ, Vaillancourt DE, MacKinnon CD. Subliminal gait initiation deficits in rapid eye movement sleep behavior disorder: a harbinger of freezing of gait? Mov Disord. 2016;31(11):1711-9.

47. Ehgoetz Martens KA, Matar E, Hall JM, Phillips J, Szeto JYY, Gouelle A, Grunstein RR, Halliday GM, Lewis SJG. Subtle gait and balance impairments occur in idiopathic rapid eye movement sleep behavior disorder. Mov Disord. 2019;34(9):1374-80

48. Hershey LA, Lichter DG. Freezing of gait in PD has a REM correlate: twice cursed with a shared pathophysiology? Neurology. 2013;81(12):1026-7.

49. Liu Y, Zhu XY, Zhang XJ, Kuo SH, Ondo WG, Wu YC. Clinical features of Parkinson's disease with and without rapid eye movement sleep behavior disorder. Transl Neurodegener. 2017:6:35.

50. Ricciardi L, Ebreo M, Graziosi A, Barbuto M, Sorbera C, Morgante L, Morgante F. Speech and gait in Parkinson's disease: when rhythm matters. Parkinsonism Relat Disord. 2016;32:42-7

51. Arena JE, Cerquetti D, Rossi M, Chaves H, Rollan C, Dossi DE, Merello M. Influence of white matter MRI hyper-intensities on acute I-dopa response in patients with Parkinson's disease. Parkinsonism Relat Disord. 2016:24:126-8.

52. Kotagal V, Albin RL, Muller ML, Koeppe RA, Frey KA, Bohnen NI. Modifiable cardiovascular risk factors and axial motor impairments in Parkinson disease Neurology. 2014;82(17):1514-20.

53. Fagan AM, Mintun MA, Mach RH, Lee SY, Dence CS, Shah AR, LaRossa GN, Spinner ML, Klunk WE, Mathis CA, et al. Inverse relation between in vivo amyloid imaging load and cerebrospinal fluid Abeta42 in humans. Ann Neurol. 2006:59(3):512-9.

54. Koehler PJ, Nonnekes J, Bloem BR. Freezing of gait before the introduction of levodopa. Lancet Neurol. 2019. https://doi.org/10.1016/S14744422(19)30091-2.

55. Nonnekes J, Snijders AH, Nutt JG, Deuschl G, Giladi N, Bloem BR. Freezing of gait: a practical approach to management. Lancet Neurol. 2015;14(7):768-78.

56. Cossu G, Ricchi V, Pilleri M, Mancini F, Murgia D, Ricchieri G, Mereu A, Melis M, Antonini A. Levodopa-carbidopa intrajejunal gel in advanced Parkinson disease with "on" freezing of gait. Neurol Sci. 2015;36(9):1683-6.

57. Rascol O, Brooks DJ, Korczyn AD, De Deyn PP, Clarke CE, Lang AE. A fiveyear study of the incidence of dyskinesia in patients with early Parkinson's disease who were treated with ropinirole or levodopa. N Engl J Med. 2000; 342(20):1484-91.

58. Nieuwboer A, Rochester L, Herman T, Vandenberghe W, Emil GE, Thomaes T, Giladi N. Reliability of the new freezing of gait questionnaire: agreement between patients with Parkinson's disease and their carers. Gait Posture. 2009;30(4):459-63.

59. Fietzek UM, Zwosta J, Schroeteler FE, Ziegler K, Ceballos-Baumann AO. Levodopa changes the severity of freezing in Parkinson's disease. Parkinsonism Relat Disord. 2013;19(10):894-6.

60. Nyholm D, Lewander T, Johansson A, Lewitt PA, Lundqvist C, Aquilonius SM Enteral levodopa/carbidopa infusion in advanced Parkinson disease: longterm exposure. Clin Neuropharmacol. 2008;31(2):63-73.

61. Devos D, French DSG. Patient profile, indications, efficacy and safety of duodenal levodopa infusion in advanced Parkinson's disease. Mov Disord. 2009:24(7):993-1000.

62. Zibetti M, Angrisano S, Dematteis F, Artusi CA, Romagnolo A, Merola A, Lopiano L. Effects of intestinal levodopa infusion on freezing of gait in Parkinson disease. J Neurol Sci. 2018;385:105-8.

63. Valldeoriola F, Grandas F, Santos-Garcia D, Regidor I, Catalan MJ, Arbelo JM, Puente V, Mir P, Parra JC. Long-term effectiveness of levodopa-carbidopa intestinal gel in 177 Spanish patients with advanced Parkinson's disease. Neurodegener Dis Manag. 2016;6(4):289-98.

64. Sensi M, Preda F, Trevisani L, Contini E, Gragnaniello D, Capone JG, Sette E, Golfre-Andreasi N, Tugnoli V, Tola MR, et al. Emerging issues on selection criteria of levodopa carbidopa infusion therapy: considerations on outcome of 28 consecutive patients. J Neural Transm (Vienna). 2014;121(6):633-42.

65. Vijiaratnam N, Hewer S, Varley S, Paul E, Bertram KL, Lee W, Ligtermoet M, Williams DR. Levodopa-carbidopa intestinal gel: is the naso-jejunal phase a redundant convention? Intern Med J. 2018;48(4):469-71.

66. Chang FC, Tsui DS, Mahant N, Wolfe N, Kim SD, Ha AD, Drury M, Griffith JM, Fung VS. 24 h Levodopa-carbidopa intestinal gel may reduce falls and "unresponsive" freezing of gait in Parkinson's disease. Parkinsonism Relat Disord. 2015;21(3):317-20. 
67. Kano O, Ikeda K, Kiyozuka T, Iwamoto K, Ito H, Kawase Y, Sato R, Fujioka T, Araki $Y$, Baba S, et al. Beneficial effect of pramipexole for motor function and depression in Parkinson's disease. Neuropsychiatr Dis Treat. 2008;4(4):707-10.

68. Ikeda K, Hirayama T, Takazawa T, Kawabe K, Iwasaki Y. Transdermal patch of rotigotine attenuates freezing of gait in patients with Parkinson's disease: an open-label comparative study of three non-ergot dopamine receptor agonists. Intern Med (Tokyo, Japan). 2016;55(19):2765-9.

69. Vaamonde Gamo J, Cabello JP, Gallardo Alcaniz MJ, Flores Barragan JM, Carrasco Garcia de Leon S, Ibanez Alonso RE. Freezing of gait unresponsive to dopaminergic stimulation in patients with severe Parkinsonism. Neurologia (Barcelona, Spain). 2010;25(1):27-31.

70. lijima M, Mitoma H, Uchiyama S, Kitagawa K. Long-term monitoring gait analysis using a wearable device in daily lives of patients with Parkinson's disease: the efficacy of Selegiline hydrochloride for gait disturbance. Front Neurol. 2017:8:542

71. Rascol O, Brooks DJ, Melamed E, Oertel W, Poewe W, Stocchi F, Tolosa E, group LS. Rasagiline as an adjunct to levodopa in patients with Parkinson's disease and motor fluctuations (LARGO, Lasting effect in Adjunct therapy with Rasagiline Given Once daily, study): a randomised, double-blind, parallel-group trial. Lancet. 2005;365(9463):947-54.

72. Cibulcik F, Benetin J, Kurca E, Grofik M, Dvorak M, Richter D, Donath V, Kothaj J, Minar M, Valkovic P. Effects of rasagiline on freezing of gait in Parkinson's disease - an open-label, multicenter study. Biomed Pap Med Fac Univ Palacky Olomouc Czech Repub. 2016;160(4):549-52.

73. Rahimi F, Roberts AC, Jog M. Patterns and predictors of freezing of gait improvement following rasagiline therapy: a pilot study. Clin Neurol Neurosurg. 2016;150:117-24.

74. Moreau C, Delval A, Defebvre L, Dujardin K, Duhamel A, Petyt G, Vuillaume I, Corvol JC, Brefel-Courbon C, Ory-Magne F, et al. Methylphenidate for gait hypokinesia and freezing in patients with Parkinson's disease undergoing subthalamic stimulation: a multicentre, parallel, randomised, placebocontrolled trial. Lancet Neurol. 2012;11(7):589-96.

75. Devos D, Krystkowiak P, Clement F, Dujardin K, Cottencin O, Waucquier N, Ajebbar K, Thielemans B, Kroumova M, Duhamel A, et al. Improvement of gait by chronic, high doses of methylphenidate in patients with advanced Parkinson's disease. J Neurol Neurosurg Psychiatry. 2007;78(5):470-5.

76. Pollak L, Dobronevsky Y, Prohorov T, Bahunker S, Rabey JM. Low dose methylphenidate improves freezing in advanced Parkinson's disease during off-state. J Neural Transm Suppl. 2007;72:145-8.

77. Espay AJ, Dwivedi AK, Payne M, Gaines L, Vaughan JE, Maddux BN, Slevin JT, Gartner M, Sahay A, Revilla FJ, et al. Methylphenidate for gait impairment in Parkinson disease: a randomized clinical trial. Neurology. 2011;76(14):1256-62.

78. Matsuura K, Kajikawa H, Tabei Kl, Satoh M, Kida H, Nakamura N, Tomimoto H. The effectiveness of istradefylline for the treatment of gait deficits and sleepiness in patients with Parkinson's disease. Neurosci Lett. 2018;662:158-61.

79. lijima M, Orimo S, Terashi H, Suzuki M, Hayashi A, Shimura H, Mitoma H, Kitagawa K, Okuma Y. Efficacy of istradefylline for gait disorders with freezing of gait in Parkinson's disease: a single-arm, open-label, prospective, multicenter study. Expert Opin Pharmacother. 2019;20(11):1405-11.

80. Takahashi M, Tabu H, Ozaki A, Hamano T, Takeshima T, group Rs. Antidepressants for depression, apathy, and gait instability in Parkinson's disease: a multicenter randomized study. Intern Med (Tokyo, Japan). 2018; 58(3):361-8.

81. Fukada K, Endo T, Yokoe M, Hamasaki T, Hazama T, Sakoda S. L-threo-3,4dihydroxyphenylserine (L-DOPS) co-administered with entacapone improves freezing of gait in Parkinson's disease. Med Hypotheses. 2013;80(2):209-12.

82. Tohgi H, Abe T, Takahashi S. The effects of L-threo-3,4dihydroxyphenylserine on the total norepinephrine and dopamine concentrations in the cerebrospinal fluid and freezing gait in parkinsonian patients. J Neural Transm Park Dis Dement Sect. 1993;5(1):27-34.

83. Malkani R, Zadikoff C, Melen O, Videnovic A, Borushko E, Simuni T. Amantadine for freezing of gait in patients with Parkinson disease. Clin Neuropharmacol. 2012;35(6):266-8.

84. Lee JY, Oh S, Kim JM, Kim JS, Oh E, Kim HT, Jeon BS, Cho JW. Intravenous amantadine on freezing of gait in Parkinson's disease: a randomized controlled trial. J Neurol. 2013;260(12):3030-8.

85. Kim YE, Yun JY, Jeon BS. Effect of intravenous amantadine on dopaminergic-drug-resistant freezing of gait. Parkinsonism Relat Disord. 2011;17(6):491-2.

86. Kim YE, Yun JY, Yang HJ, Kim HJ, Gu N, Yoon SH, Cho JY, Jeon BS. Intravenous amantadine for freezing of gait resistant to dopaminergic therapy: a randomized, double-blind, placebo-controlled, cross-over clinical trial. PLoS One. 2012;7(11):e48890.

87. Jankovic J. Atomoxetine for freezing of gait in Parkinson disease. J Neurol Sci. 2009;284(1-2):177-8.

88. Revuelta GJ, Embry A, Elm JJ, Gregory C, Delambo A, Kautz S, Hinson VK. Pilot study of atomoxetine in patients with Parkinson's disease and dopaunresponsive freezing of gait. Transl Neurodegener. 2015;4:24.

89. Litvinenko IV, Odinak MM, Mogil'naia VI, Emelin A. Efficacy and safety of galantamine (reminyl) in the treatment of dementia in patients with Parkinson's disease (open-label controlled trial). Zh Nevrol Psikhiatr Im S S Korsakova. 2007;107(12):25-33.

90. Henderson EJ, Lord SR, Brodie MA, Gaunt DM, Lawrence AD, Close JC, Whone AL, Ben-Shlomo Y. Rivastigmine for gait stability in patients with Parkinson's disease (ReSPonD): a randomised, double-blind, placebocontrolled, phase 2 trial. Lancet Neurol. 2016;15(3):249-58.

91. Gurevich T, Peretz C, Moore O, Weizmann N, Giladi N. The effect of injecting botulinum toxin type a into the calf muscles on freezing of gait in Parkinson's disease: a double blind placebo-controlled pilot study. Mov Disord. 2007;22(6):880-3.

92. Wieler M, Camicioli R, Jones CA, Martin WR. Botulinum toxin injections do not improve freezing of gait in Parkinson disease. Neurology. 2005;65(4): 626-8.

93. Giladi N, Gurevich T, Shabtai H, Paleacu D, Simon ES. The effect of botulinum toxin injections to the calf muscles on freezing of gait in parkinsonism: a pilot study. J Neurol. 2001;248(7):572-6.

94. Vastik M, Hok P, Hlustik P, Otruba P, Tudos Z, Kanovsky P. Botulinum toxin treatment of freezing of gait in Parkinson's disease patients as reflected in functional magnetic resonance imaging of leg movement. Neuro Endocrinol Lett. 2016;37(2):147-53.

95. Fernandez HH, Lannon MC, Trieschmann ME, Friedman JH. Botulinum toxin type B for gait freezing in Parkinson's disease. Med Sci Monit. 2004;10(7): Cr282-4.

96. Amboni M, Stocchi F, Abbruzzese G, Morgante L, Onofrj M, Ruggieri S, Tinazzi M, Zappia M, Attar M, Colombo D, et al. Prevalence and associated features of self-reported freezing of gait in Parkinson disease: the DEEP FOG study. Parkinsonism Relat Disord. 2015;21(6):644-9.

97. Espay AJ, Fasano A, van Nuenen BF, Payne MM, Snijders AH, Bloem BR. "On" state freezing of gait in Parkinson disease: a paradoxical levodopa-induced complication. Neurology. 2012;78(7):454-7.

98. Olanow CW, Kieburtz K, Odin P, Espay AJ, Standaert DG, Fernandez HH, Vanagunas A, Othman AA, Widnell KL, Robieson WZ, et al. Continuous intrajejunal infusion of levodopa-carbidopa intestinal gel for patients with advanced Parkinson's disease: a randomised, controlled, double-blind, double-dummy study. Lancet Neurol. 2014;13(2):141-9.

99. Fernandez HH, Standaert DG, Hauser RA, Lang AE, Fung VS, Klostermann F, Lew MF, Odin P, Steiger M, Yakupov EZ, et al. Levodopa-carbidopa intestinal gel in advanced Parkinson's disease: final 12-month, open-label results. Mov Disord. 2015;30(4):500-9.

100. Serrao M, Ranavolo A, Conte C, Davassi C, Mari S, Fasano A, Chini G, Coppola G, Draicchio F, Pierelli F. Effect of 24-h continuous rotigotine treatment on stationary and non-stationary locomotion in de novo patients with Parkinson disease in an open-label uncontrolled study. J Neurol. 2015;262(11):2539-47.

101. Ondo W, Hunter C, Almaguer M, Gancher S, Jankovic J. Efficacy and tolerability of a novel sublingual apomorphine preparation in patients with fluctuating Parkinson's disease. Clin Neuropharmacol. 1999;22(1): $1-4$.

102. Brodsky MA, Park BS, Nutt JG. Effects of a dopamine agonist on the pharmacodynamics of levodopa in Parkinson disease. Arch Neurol. 2010; 67(1):27-32.

103. Shoulson I, Oakes D, Fahn S, Lang A, Langston JW, LeWitt P, Olanow CW, Penney JB, Tanner C, Kieburtz K, et al. Impact of sustained deprenyl (selegiline) in levodopa-treated Parkinson's disease: a randomized placebocontrolled extension of the deprenyl and tocopherol antioxidative therapy of parkinsonism trial. Ann Neurol. 2002;51(5):604-12.

104. Zhang Z, Wang J, Chen S, Liu C, Zhang B, Peng R, Sun S, Sun X, Zhao G, Qu $Q$, et al. Efficacy and safety of rasagiline in Chinese patients with early Parkinson's disease: a randomized, double-blind, parallel, placebo-controlled, fixed-dose study. Transl Neurodegener. 2018;7:32.

105. Zhang Z, Shao M, Chen S, Liu C, Peng R, Li Y, Wang J, Zhu S, Qu Q, Zhang $X$, et al. Adjunct rasagiline to treat Parkinson's disease with motor 
fluctuations: a randomized, double-blind study in China. Transl Neurodegener. 2018;7:14

106. Stern MB, Marek KL, Friedman J, Hauser RA, LeWitt PA, Tarsy D, Olanow CW. Double-blind, randomized, controlled trial of rasagiline as monotherapy in early Parkinson's disease patients. Mov Disord. 2004;19(8):916-23.

107. Kitagawa M, Houzen $H$, Tashiro K. Effects of caffeine on the freezing of gait in Parkinson's disease. Mov Disord. 2007;22(5):710-2.

108. LeWitt PA, Guttman M, Tetrud JW, Tuite PJ, Mori A, Chaikin P, Sussman NM, Group USS. Adenosine A2A receptor antagonist istradefylline (KW-6002) reduces "off" time in Parkinson's disease: a double-blind, randomized, multicenter clinical trial (6002-US-005). Ann Neurol. 2008;63(3):295-302.

109. Bohnen NI, Frey KA, Studenski S, Kotagal V, Koeppe RA, Constantine GM, Scott PJ, Albin RL, Muller ML. Extra-nigral pathological conditions are common in Parkinson's disease with freezing of gait: an in vivo positron emission tomography study. Mov Disord. 2014:29(9):1118-24.

110. Pinto de Souza C, Hamani C, Oliveira Souza C, Lopez Contreras WO, Dos Santos Ghilardi MG, Cury RG, Reis Barbosa E, Jacobsen Teixeira M, Talamoni Fonoff E. Spinal cord stimulation improves gait in patients with Parkinson's disease previously treated with deep brain stimulation. Mov Disord. 2017; 32(2):278-82.

111. Samotus O, Parrent A, Jog M. Spinal cord stimulation therapy for gait dysfunction in advanced Parkinson's disease patients. Mov Disord. 2018; 33(5):783-92.

112. Jacobs JV, Lou JS, Kraakevik JA, Horak FB. The supplementary motor area contributes to the timing of the anticipatory postural adjustment during step initiation in participants with and without Parkinson's disease. Neuroscience. 2009;164(2):877-85.

113. Takakusaki K, Habaguchi T, Ohtinata-Sugimoto J, Saitoh K, Sakamoto T. Basal ganglia efferents to the brainstem centers controlling postural muscle tone and locomotion: a new concept for understanding motor disorders in basal ganglia dysfunction. Neuroscience. 2003;119(1):293-308.

114. Takakusaki K. Functional neuroanatomy for posture and gait control. J Mov Disord. 2017;10(1):1-17.

115. Brudzynski SM, Wu M, Mogenson GJ. Decreases in rat locomotor activity as a result of changes in synaptic transmission to neurons within the mesencephalic locomotor region. Can J Physiol Pharmacol. 1993;71(5-6): 394-406.

116. de Lima-Pardini AC, Coelho DB, Souza CP, Souza CO, Ghilardi M, Garcia T, Voos M, Milosevic M, Hamani C, Teixeira LA, et al. Effects of spinal cord stimulation on postural control in Parkinson's disease patients with freezing of gait. Elife. 2018;7. https://doi.org/10.7554/eLife.37727.

117. Fonoff ET, de Lima-Pardini AC, Coelho DB, Monaco BA, Machado B, Pinto de Souza C, Dos Santos Ghilardi MG, Hamani C. Spinal cord stimulation for freezing of gait: from bench to bedside. Front Neurol. 2019;10:905.

118. Schlenstedt C, Shalash A, Muthuraman M, Falk D, Witt K, Deuschl G. Effect of high-frequency subthalamic neurostimulation on gait and freezing of gait in Parkinson's disease: a systematic review and meta-analysis. Eur J Neurol. 2017;24(1):18-26.

119. Zibetti M, Merola A, Rizzi L, Ricchi V, Angrisano S, Azzaro C, Artusi CA, Arduino N, Marchisio A, Lanotte M, et al. Beyond nine years of continuous subthalamic nucleus deep brain stimulation in Parkinson's disease. Mov Disord. 2011;26(13):2327-34.

120. Rizzone MG, Fasano A, Daniele A, Zibetti M, Merola A, Rizzi L, Piano C, Piccininni C, Romito LM, Lopiano L, et al. Long-term outcome of subthalamic nucleus DBS in Parkinson's disease: from the advanced phase towards the late stage of the disease? Parkinsonism Relat Disord. 2014;20(4): 376-81.

121. Li J, Zhang Y, Li Y. Long-term follow-up of bilateral subthalamic nucleus stimulation in Chinese Parkinson's disease patients. Br J Neurosurg. 2015; 29(3):329-33.

122. Krause M, Fogel W, Mayer P, Kloss M, Tronnier V. Chronic inhibition of the subthalamic nucleus in Parkinson's disease. J Neurol Sci. 2004;219(1-2):119-24.

123. Davis JT, Lyons KE, Pahwa R. Freezing of gait after bilateral subthalamic nucleus stimulation for Parkinson's disease. Clin Neurol Neurosurg. 2006; 108(5):461-4.

124. Krack P, Batir A, Van Blercom N, Chabardes S, Fraix V, Ardouin C, Koudsie A, Limousin PD, Benazzouz A, LeBas JF, et al. Five-year follow-up of bilateral stimulation of the subthalamic nucleus in advanced Parkinson's disease. N Engl J Med. 2003;349(20):1925-34.

125. Visser-Vandewalle V, van der Linden C, Temel Y, Celik H, Ackermans L, Spincemaille G, Caemaert J. Long-term effects of bilateral subthalamic nucleus stimulation in advanced Parkinson disease: a four year follow-up study. Parkinsonism Relat Disord. 2005;11(3):157-65.

126. Ferraye MU, Debu B, Fraix V, Xie-Brustolin J, Chabardes S, Krack P, Benabid AL, Pollak P. Effects of subthalamic nucleus stimulation and levodopa on freezing of gait in Parkinson disease. Neurology. 2008;70(16 Pt 2):1431-7.

127. Niu L, Ji LY, Li JM, Zhao DS, Huang G, Liu WP, Qu Y, Ma LT, Ji XT. Effect of bilateral deep brain stimulation of the subthalamic nucleus on freezing of gait in Parkinson's disease. J Int Med Res. 2012;40(3):1108-13.

128. Vercruysse S, Vandenberghe W, Munks L, Nuttin B, Devos H, Nieuwboer A. Effects of deep brain stimulation of the subthalamic nucleus on freezing of gait in Parkinson's disease: a prospective controlled study. J Neurol Neurosurg Psychiatry. 2014;85(8):871-7.

129. Adams C, Keep M, Martin K, McVicker J, Kumar R. Acute induction of levodopa-resistant freezing of gait upon subthalamic nucleus electrode implantation. Parkinsonism Relat Disord. 2011;17(6):488-90.

130. van Nuenen BF, Esselink RA, Munneke M, Speelman JD, van Laar T, Bloem BR. Postoperative gait deterioration after bilateral subthalamic nucleus stimulation in Parkinson's disease. Mov Disord. 2008;23(16):2404-6.

131. Fleury V, Pollak P, Gere J, Tommasi G, Romito L, Combescure C, Bardinet E, Chabardes S, Momjian S, Krainik A, et al. Subthalamic stimulation may inhibit the beneficial effects of levodopa on akinesia and gait. Mov Disord. 2016;31(9):1389-97.

132. Kim R, Kim HJ, Kim A, Kim Y, Kim AR, Shin CW, Paek SH, Jeon B. Depression may negatively affect the change in freezing of gait following subthalamic nucleus stimulation in Parkinson's disease. Parkinsonism Relat Disord. 2017; 44:133-6.

133. Moreau C, Defebvre L, Destee A, Bleuse S, Clement F, Blatt IL, Krystkowiak P, Devos D. STN-DBS frequency effects on freezing of gait in advanced Parkinson disease. Neurology. 2008;71(2):80-4.

134. Xie T, Vigil J, MacCracken E, Gasparaitis A, Young J, Kang W, Bernard J, Warnke P, Kang UJ. Low-frequency stimulation of STN-DBS reduces aspiration and freezing of gait in patients with PD. Neurology. 2015;84(4): $415-20$

135. Xie T, Bloom L, Padmanaban M, Bertacchi B, Kang W, MacCracken E, Dachman A, Vigil J, Satzer D, Zadikoff C, et al. Long-term effect of low frequency stimulation of STN on dysphagia, freezing of gait and other motor symptoms in PD. J Neurol Neurosurg Psychiatry. 2018;89(9):989-94.

136. Phibbs FT, Arbogast PG, Davis TL. 60-Hz frequency effect on gait in Parkinson's disease with subthalamic nucleus deep brain stimulation. Neuromodulation. 2014;17(8):717-20 discussion 720.

137. Sidiropoulos C, Walsh R, Meaney C, Poon YY, Fallis M, Moro E. Lowfrequency subthalamic nucleus deep brain stimulation for axial symptoms in advanced Parkinson's disease. J Neurol. 2013;260(9): 2306-11.

138. Xie T, Padmanaban M, Bloom L, MacCracken E, Bertacchi B, Dachman A, Warnke P. Effect of low versus high frequency stimulation on freezing of gait and other axial symptoms in Parkinson patients with bilateral STN DBS: a mini-review. Transl Neurodegener. 2017;6:13.

139. Xie T, Kang UJ. Comments on the recent viewpoint article on low-frequency deep brain stimulation for Parkinson's disease. Mov Disord. 2017;32(1):176.

140. Chen S, Gao G, Feng T, Zhang J, Chinese Medical Association Neurosurgery Branch of Functional Neurosurgery G, Chinese Medical Association Neurology Branch of Parkinson's D, Movement Disorders G, Chinese Physician Association Neurosurgeon Branch of Functional Neurosurgery Expert C, Chinese Physician Association Neurologist Branch of Parkinson's D, Movement Disorders Professional C, et al. Chinese expert consensus on programming deep brain stimulation for patients with Parkinson's disease. Transl Neurodegener. 2018;7:11.

141. Mestre TA, Sidiropoulos C, Hamani C, Poon YY, Lozano AM, Lang AE, Moro E. Long-term double-blinded unilateral pedunculopontine area stimulation in Parkinson's disease. Mov Disord. 2016;31(10):1570-4.

142. Thevathasan W, Debu B, Aziz T, Bloem BR, Blahak C, Butson C, Czernecki V Foltynie T, Fraix V, Grabli D, et al. Pedunculopontine nucleus deep brain stimulation in Parkinson's disease: a clinical review. Mov Disord. 2018;33(1): $10-20$.

143. Welter ML, Demain A, Ewenczyk C, Czernecki V, Lau B, El Helou A, Belaid H, Yelnik J, Francois C, Bardinet E, et al. PPNa-DBS for gait and balance disorders in Parkinson's disease: a double-blind, randomised study. J Neurol. 2015;262(6):1515-25

144. Thevathasan W, Cole MH, Graepel CL, Hyam JA, Jenkinson N, Brittain JS, Coyne TJ, Silburn PA, Aziz TZ, Kerr G, et al. A spatiotemporal analysis of gait 
freezing and the impact of pedunculopontine nucleus stimulation. Brain. 2012;135(Pt 5):1446-54

145. Thevathasan W, Coyne TJ, Hyam JA, Kerr G, Jenkinson N, Aziz TZ, Silburn PA. Pedunculopontine nucleus stimulation improves gait freezing in Parkinson disease. Neurosurgery. 2011;69(6):1248-53 discussion 1254.

146. Moro E, Hamani C, Poon YY, Al-Khairallah T, Dostrovsky JO, Hutchison WD, Lozano AM. Unilateral pedunculopontine stimulation improves falls in Parkinson's disease. Brain. 2010;133(Pt 1):215-24.

147. Ferraye MU, Debu B, Fraix V, Goetz L, Ardouin C, Yelnik J, Henry-Lagrange C, Seigneuret E, Piallat B, Krack P, et al. Effects of pedunculopontine nucleus area stimulation on gait disorders in Parkinson's disease. Brain. 2010;133(Pt 1):205-14.

148. Thevathasan W, Pogosyan A, Hyam JA, Jenkinson N, Foltynie T, Limousin P, Bogdanovic M, Zrinzo L, Green AL, Aziz TZ, et al. Alpha oscillations in the pedunculopontine nucleus correlate with gait performance in parkinsonism. Brain. 2012;135(Pt 1):148-60.

149. Weiss D, Walach M, Meisner C, Fritz M, Scholten M, Breit S, Plewnia C, Bender B, Gharabaghi A, Wachter T, et al. Nigral stimulation for resistant axial motor impairment in Parkinson's disease? A randomized controlled trial. Brain. 2013;136(Pt 7):2098-108.

150. Valldeoriola F, Munoz E, Rumia J, Roldan P, Camara A, Compta Y, Marti MJ, Tolosa E. Simultaneous low-frequency deep brain stimulation of the substantia nigra pars reticulata and high-frequency stimulation of the subthalamic nucleus to treat levodopa unresponsive freezing of gait in Parkinson's disease: a pilot study. Parkinsonism Relat Disord. 2019;60:153-7.

151. Farrand AQ, Helke KL, Gregory RA, Gooz M, Hinson VK, Boger HA. Vagus nerve stimulation improves locomotion and neuronal populations in a model of Parkinson's disease. Brain Stimul. 2017;10(6):1045-54.

152. Mondal B, Choudhury S, Simon B, Baker MR, Kumar H. Noninvasive vagus nerve stimulation improves gait and reduces freezing of gait in Parkinson's disease. Mov Disord. 2019;34(6):917-8.

153. Kim YW, Shin IS, Moon HI, Lee SC, Yoon SY. Effects of non-invasive brain stimulation on freezing of gait in Parkinsonism: a systematic review with meta-analysis. Parkinsonism Relat Disord. 2019;64:82-9.

154. Mi TM, Garg S, Ba F, Liu AP, Wu T, Gao LL, Dan XJ, Chan P, McKeown MJ. High-frequency rTMS over the supplementary motor area improves freezing of gait in Parkinson's disease: a randomized controlled trial. Parkinsonism Relat Disord. 2019:68:85-90.

155. Kim SJ, Paeng SH, Kang SY. Stimulation in supplementary motor area versus motor cortex for freezing of gait in Parkinson's disease. J Clin Neurol. 2018: 14(3):320-6.

156. Valentino F, Cosentino G, Brighina F, Pozzi NG, Sandrini G, Fierro B, Savettieri G, D'Amelio M, Pacchetti C. Transcranial direct current stimulation for treatment of freezing of gait: a cross-over study. Mov Disord. 2014;29(8): 1064-9.

157. Dagan M, Herman T, Harrison R, Zhou J, Giladi N, Ruffini G, Manor B, Hausdorff JM. Multitarget transcranial direct current stimulation for freezing of gait in Parkinson's disease. Mov Disord. 2018;33(4):642-6.

158. Lu C, Amundsen Huffmaster SL, Tuite PJ, MacKinnon CD. The effects of anodal tDCS over the supplementary motor area on gait initiation in Parkinson's disease with freezing of gait: a pilot study. J Neurol. 2018;265(9): 2023-32.

159. Nieuwboer A, Kwakkel G, Rochester $L$, Jones $D$, van Wegen E, Willems AM, Chavret F, Hetherington V, Baker K, Lim I. Cueing training in the home improves gait-related mobility in Parkinson's disease: the RESCUE trial. J Neurol Neurosurg Psychiatry. 2007;78(2):134-40.

160. Barthel C, Nonnekes J, van Helvert M, Haan R, Janssen A, Delval A, Weerdesteyn V, Debu B, van Wezel R, Bloem BR, et al. The laser shoes: a new ambulatory device to alleviate freezing of gait in Parkinson disease. Neurology. 2018;90(2):e164-71.

161. McCandless PJ, Evans BJ, Janssen J, Selfe J, Churchill A, Richards J. Effect of three cueing devices for people with Parkinson's disease with gait initiation difficulties. Gait Posture. 2016;44:7-11.

162. Zhao Y, Nonnekes J, Storcken EJ, Janssen S, van Wegen EE, Bloem BR, Dorresteijn LD, van Vugt JP, Heida T, van Wezel RJ. Feasibility of external rhythmic cueing with the Google Glass for improving gait in people with Parkinson's disease. J Neurol. 2016;263(6):1156-65.

163. Sweeney D, Quinlan LR, Browne P, Richardson M, Meskell P, ÓLaighin G. A technological review of wearable cueing devices addressing freezing of gait in Parkinson's disease. Sensors (Basel). 2019;19(6). https://doi.org/10.3390/ s19061277.
164. Frazzitta G, Maestri R, Uccellini D, Bertotti G, Abelli P. Rehabilitation treatment of gait in patients with Parkinson's disease with freezing: a comparison between two physical therapy protocols using visual and auditory cues with or without treadmill training. Mov Disord. 2009;24(8): $1139-43$.

165. Cheng FY, Yang YR, Wu YR, Cheng SJ, Wang RY. Effects of curved-walking training on curved-walking performance and freezing of gait in individuals with Parkinson's disease: a randomized controlled trial. Parkinsonism Relat Disord. 2017:43:20-6.

166. Lo AC, Chang VC, Gianfrancesco MA, Friedman JH, Patterson TS, Benedicto DF. Reduction of freezing of gait in Parkinson's disease by repetitive robotassisted treadmill training: a pilot study. J Neuroeng Rehabil. 2010;7:51.

167. Barbe MT, Cepuran F, Amarell M, Schoenau E, Timmermann L. Long-term effect of robot-assisted treadmill walking reduces freezing of gait in Parkinson's disease patients: a pilot study. J Neurol. 2013;260(1):296-8.

168. Pilleri M, Weis L, Zabeo L, Koutsikos K, Biundo R, Facchini S, Rossi S, Masiero $\mathrm{S}$, Antonini A. Overground robot assisted gait trainer for the treatment of drug-resistant freezing of gait in Parkinson disease. J Neurol Sci. 2015;355(12):75-8.

169. Zhu Z, Yin M, Cui L, Zhang Y, Hou W, Li Y, Zhao H. Aquatic obstacle training improves freezing of gait in Parkinson's disease patients: a randomized controlled trial. Clin Rehabil. 2018:32(1):29-36.

170. Santos L, Fernandez-Rio J, Winge K, Barragan-Perez B, Rodriguez-Perez V, Gonzalez-Diez V, Blanco-Traba M, Suman OE, Philip Gabel C, RodriguezGomez J. Effects of supervised slackline training on postural instability, freezing of gait, and falls efficacy in people with Parkinson's disease. Disabil Rehabil. 2017;39(16):1573-80

171. Stummer C, Dibilio V, Overeem S, Weerdesteyn V, Bloem BR, Nonnekes J. The walk-bicycle: a new assistive device for Parkinson's patients with freezing of gait? Parkinsonism Relat Disord. 2015;21(7):755-7.

172. Agosta F, Gatti R, Sarasso E, Volonte MA, Canu E, Meani A, Sarro L, Copetti $M$, Cattrysse E, Kerckhofs $E$, et al. Brain plasticity in Parkinson's disease with freezing of gait induced by action observation training. J Neurol. 2017; 264(1):88-101.

173. Pelosin E, Avanzino L, Bove M, Stramesi P, Nieumboer A, Abbruzzese G. Action observation improves freezing of gait in patients with Parkinson's disease. Neurorehabil Neural Repair. 2010;24(8):746-52.

174. Cosentino C, Baccini M, Putzolu M, Ristori D, Avanzino L, Pelosin E. Effectiveness of physiotherapy on freezing of gait in Parkinson's disease: a systematic review and meta-analyses. Mov Disord. 2019. https://doi.org/10. 1002/mds.27936.

Ready to submit your research? Choose BMC and benefit from:

- fast, convenient online submission

- thorough peer review by experienced researchers in your field

- rapid publication on acceptance

- support for research data, including large and complex data types

- gold Open Access which fosters wider collaboration and increased citations

- maximum visibility for your research: over $100 \mathrm{M}$ website views per year

At $\mathrm{BMC}$, research is always in progress.

Learn more biomedcentral.com/submissions 